\title{
DNA uptake by cell wall-deficient bacteria reveals a putative ancient macromolecule uptake mechanism
}

\section{Renee Kapteijn}

Leiden University

Shraddha Shitut

Leiden University

Dennis Aschmann

Leiden University

\section{Le Zhang}

Institute of Biology, Leiden University

Marit de Beer

RadboudUMC

Deniz Daviran

RadboudUMC

Rona Roverts

RadboudUMC

\section{Anat Akiva}

Radboud Institute for molecular life sciences, Radboudumc https://orcid.org/0000-0003-0414-889X

\section{Gilles van Wezel}

Leiden University https://orcid.org/0000-0003-0341-1561

\section{Alexander Kros}

Leiden University https://orcid.org/0000-0002-3983-3048

Dennis Claessen ( $\square$ D.Claessen@biology.leidenuniv.nl )

Leiden University https://orcid.org/0000-0002-0789-2633

\section{Article}

Keywords: cell wall-deficiency, natural transformation, L-forms, endocytosis, horizontal gene transfer, cryo FIB-SEM

Posted Date: March 3rd, 2022

DOI: https://doi.org/10.21203/rs.3.rs-1365123/v1

License: (c) (i) This work is licensed under a Creative Commons Attribution 4.0 International License. 
Version of Record: A version of this preprint was published at Nature Communications on September 22nd, 2022. See the published version at https://doi.org/10.1038/s41467-022-33054-w. 
1 DNA uptake by cell wall-deficient bacteria reveals a putative ancient macromolecule

2 uptake mechanism

3 Renée Kapteijn ${ }^{1}$, Shraddha Shitut ${ }^{1}$, Dennis Aschmann², Le Zhang ${ }^{1}$, Marit de Beer ${ }^{3}$, Deniz

4 Daviran $^{3}$, Rona Roverts ${ }^{3}$, Anat Akiva ${ }^{3}$, Gilles P. van Wezel ${ }^{1, *}$, Alexander $\mathrm{Kros}^{2}$, Dennis

5 Claessen $1,4, *$

6

$7{ }^{1}$ Molecular Biotechnology, Institute of Biology, Leiden University, Sylviusweg 72, 2333 BE

8 Leiden, The Netherlands.

9 2Department of Supramolecular and Biomaterials Chemistry, Leiden Institute of Chemistry,

10 Leiden University, Einsteinweg 55, 2333 CC Leiden, The Netherlands

11 Electron Microscopy Center, Radboudumc Technology Center Microscopy, Nijmegen, The

12 Netherlands

$13 \quad{ }^{4}$ Lead contact

$14 *$ Correspondence:

15 G.Wezel@biology.leidenuniv.nl (G.P.v.W.), D.Claessen@biology.leidenuniv.nl (D.C.)

16

17

18 Keywords: cell wall-deficiency; natural transformation; L-forms; endocytosis;

19 horizontal gene transfer; cryo FIB-SEM 


\section{SUMMARY}

21 Horizontal gene transfer in bacteria is widely believed to occur via three main mechanisms:

22 conjugation, transduction and transformation. These mechanisms facilitate the passage of DNA

23 across the protective cell wall using sophisticated machinery. We present here a new

24 mechanism of DNA uptake that is independent of canonical DNA uptake machineries and is

25 used by bacteria that live without a cell wall. We show that the cell wall-deficient bacteria

26 engulf extracellular material, whereby intracellular vesicles are formed, and DNA is

27 internalized. This mechanism is not specific to DNA, and allows uptake of other 28 macromolecules and even $125 \mathrm{~nm}$ lipid nanoparticles (LNPs). Uptake was prevented by

29 molecules known to inhibit eukaryotic endocytosis, suggesting this to be an energy-dependent

30 process. Given that cell wall-deficient bacteria are considered a model for early life forms, our

31 work provides a possible mechanism for primordial cells to acquire new genetic material or

32 food before invention of the bacterial cell wall. 


\section{INTRODUCTION}

34 Bacteria are constantly exposed to changing environmental conditions and rely on their cell envelope for protection. The cell envelope consists of a cell membrane and a cell wall to separate the internal from the external environment. The cell membrane is a phospholipid bilayer that encloses the cytoplasm and functions as a selective barrier. The cell wall consists of a thick peptidoglycan (PG) layer for Gram-positive bacteria and a thinner PG layer surrounded by an outer membrane for Gram-negative bacteria. The peptidoglycan layer is an important mesh-like structure that not only provides protection against mechanical stress and turgor pressure, but also defines cell shape and rigidity.

To facilitate the selective passage of macromolecules across the cell envelope, bacteria have evolved specialized and sophisticated transport systems (Costa et al., 2015; Forster and Marquis, 2012). For instance, naturally transformable bacteria rely on protein complexes for DNA uptake, with components similar to type IV pili or type II secretion systems. Active transport of DNA across the cell wall is facilitated by the retraction of pilus structures that bind DNA (Chen and Dubnau, 2004; Ellison et al., 2018). Alternatively, the assembly and release of short pilus structures are thought to create transient holes in the PG layer that allow DNA to diffuse to the cell membrane (Muschiol et al., 2015). DNA binding and pore-forming proteins are then used to translocate the DNA across the cell membrane.

Although the cell wall is a vital structure for most bacteria, some bacteria naturally lack a cell wall, or can shed their wall under specific conditions. Examples include the members of the Mollicutes, that are parasitic and live in specific osmotically protective environments such as human mucosal surfaces or the phloem sieve tubes of plants (Stülke et al., 2009). Prolonged exposure to environmental stressors such as cell wall-targeting agents generates so-called Lforms, which are cells that proliferate without their cell wall. Reproduction of L-forms is driven by the upregulation of membrane synthesis and is characterized by blebbing, tubulation and 
58 vesiculation (Mercier et al., 2013; Ramijan et al., 2018). These primitive cell-like 59 characteristics make L-forms an attractive model system to study the evolution of early life

60 (Briers et al., 2012b; Errington et al., 2016). How the absence of the cell wall affects uptake of 61 macromolecules such as DNA from the environment is unknown.

62 In this study we show that L-forms of the filamentous actinomycete Kitasatospora 63 viridifaciens can naturally take up DNA independent of the canonical DNA translocation 64 machinery. Instead, uptake is facilitated by a new mechanism of horizontal gene transfer that 65 involves the invagination of the cell membrane leading to internal vesicle formation. 66 Furthermore we show that this mechanism is robust and allows the non-specific uptake of other 67 macromolecules from the environment as well. Given that L-forms are considered a model for 68 early cellular life, our work provides insight into how such ancient cells may have acquired 69 large biomolecules and nanoparticles from the environment without the need for complex transport machineries. 


\section{RESULTS}

\section{Natural and artificial DNA uptake by wall-deficient cells}

$K$. viridifaciens is a mycelium-forming bacterium that can extrude temporary wall-deficient cells, called S-cells, under conditions of osmotic stress (Ramijan et al., 2018). These cells can only proliferate by rebuilding the cell wall and reverting to a mycelial mode-of-growth, similar to artificially created cell-wall deficient protoplasts. Prolonged incubation of S-cells in high osmotic pressure can induce the switch to an L-form state that allows reproduction without rebuilding the cell wall. It is unknown whether these cell wall-deficient cells can take up DNA via natural transformation. To analyse this, protoplasts, S-cells and L-forms (alpha) were incubated with plasmid DNA, and subsequently plated on selective and non-selective medium (Figure 1A). Notably, L-forms were consistently able to take up DNA, unlike protoplasts or Scells (Figure 1B). This DNA uptake ability was not restricted to the penicillin-induced L-forms (lines alpha and delta), as the osmotically induced L-form (line M1) (Ramijan et al., 2018) could also take up plasmid DNA. No transformants were obtained with alpha when intact or fragmented genomic DNA was used (Figure S1A). While natural transformation was restricted to L-forms, all wall-deficient cells could be chemically transformed using polyethylene glycol (PEG), with protoplasts, S-cells and L-forms having an average transformation efficiency between $1.7-2.5 \%$ (Figure S1B). The addition of PEG also enabled transformation of alpha with genomic DNA, even if this was present in a crude cell extract. On the other hand, use of methylated DNA prevented transformation, indicating that transformation is possible with different types of DNA, but can be limited by the presence of a different methylation pattern (Figure S1C). By contrast, walled cells could not be transformed either with or without PEG (Figure 1B and Figure S1B). These results show that proliferating wall-deficient L-forms can take up DNA naturally, while walled cells and transient wall-deficient S-cells and protoplasts cannot. 


\section{L-forms take up DNA in the absence of canonical DNA translocation machinery}

97 Naturally transformable bacteria use a specialized DNA translocation machinery with similarities to type IV pili or type II secretion systems to take up external DNA (Chen and Dubnau, 2004). Similar components of this canonical system might also be involved in DNA uptake by L-forms. A BlastP search using the DNA-binding protein ComEA and channel

101 protein ComEC of the naturally transformable bacterium Bacillus subtilis against $K$. viridifaciens yielded two significant hits: BOQ63_29625 (helix-hairpin-helix domaincontaining protein) and BOQ63_29630 (ComEC/Rec2 family competence protein), respectively (Figure 1C and Table S1). The B. subtilis helicase/DNA translocase ComFA resulted in a hit to a putative Mfd-encoding gene (BOQ63_20315), a widely conserved bacterial protein that mediates transcription-coupled DNA repair (Roberts and Park, 2004). No other orthologues were found that correlated to proteins involved in DNA transport across the cell envelope for B. subtilis, the Gram-negative Neisseria gonorrhoeae (Kruger and Stingl, 2011) or for the T4SS-related DNA uptake system of Helicobacter pylori (Gilbreath et al., 2011) (Table S1). L-forms lack an intact peptidoglycan-based cell wall and therefore DNA must only cross the cell membrane for internalization. As ComEA and ComEC function in

112 DNA transport across the cell membrane (Friedrich et al., 2001; Inamine and Dubnau, 1995;

113 Kruger and Stingl, 2011) we wondered whether these proteins are involved in DNA uptake in

114 L-forms. Therefore, we replaced the putative comEC and comEA genes in the L-form strain 115 alpha by an apramycin resistance cassette (Figure S1D). Strikingly, the simultaneous deletion

116 of the comEA and comEC genes did not affect the natural transformation efficiency (two-tailed 117 independent t-test, $t(8)=1.572, P=0.155)$, indicating that DNA uptake by L-forms occurs 118 independent of this canonical DNA translocation machinery (Figure 1D). 
122 One of the factors controlling the development of competence for DNA uptake in B. subtilis is

123 the growth phase (Dubnau, 1991; Hamoen et al., 2003). To study if culture age is also affecting

124 the DNA uptake ability of L-forms, differently aged cultures were subjected to a natural

125 transformation assay. One-day old cultures of alpha take up DNA more easily than 3- or 7-day

126 old cultures (one-way ANOVA, F $(2,9)=12.16$, Tukey post-hoc test, $P=.006$ and .005

127 respectively) (Figure 1E). It is not unlikely that differences in membrane properties that occur

128 during cellular growth may in turn affect the DNA uptake ability. Membrane fluidity is a

129 measure for the average viscosity of the lipid bilayer, which can affect the positioning and

130 movement of proteins and lipids within the membrane (Lenaz, 1987). A higher membrane

131 fluidity is characterized by increased fatty acid disorder, lower lipid packing and higher

132 diffusion rates, which can lead to increased membrane permeabilization (Chapman, 1975;

133 Lande et al., 1995). Analysis of the membrane fluidity of the differently aged cultures indicated

134 that the increased DNA uptake ability may correlate positively with the fluidity of the

135 membrane, as deduced from the generalized polarization (GP) (Scheinpflug et al., 2017)

136 (Figure 1F), although no statistical significant differences were observed (Welch ANOVA,

$137 \mathrm{~F}(2,2.798)$, with Games-Howell post-hoc test: $1-3$ day $P=.068 ; 1-7$ day $P=0.134 ; 3-7$ day $P$

$138=0.711)$. A relatively low fluidity might explain why temporary wall-deficient protoplasts and

139 S-cells cannot take up DNA naturally. However, the fluidity of protoplasts was within the range

140 of 1- to 7-day-old cultures as measured using a plate assay (Figure S1E). Subsequent analysis

141 of the GP by fluorescence microscopy imaging showed that although protoplasts and S-cells

142 tend to have less fluid membranes, these values stay within the range of the membrane fluidity

143 of 1- to 7-day old L-forms (Figure S1F). Therefore, although membrane fluidity may contribute

144 to efficient DNA uptake, it is not sufficient to explain this process. 


\section{L-forms take up DNA via an endocytosis-like mechanism}

147 To further investigate the mechanism facilitating DNA uptake by L-forms, we added Cy5148 labelled plasmid DNA to L-forms expressing cytosolic eGFP. Labelled plasmid DNA was 149 found either on the outside of the L-form cell membrane, or within apparent internal vesicles 150 (Figure 2A and control Figure S2A). As these internal vesicles were devoid of eGFP, we reasoned that they could have originated by an invagination process of the membrane, whereby extracellular material becomes trapped inside the vesicles. To test this directly, we incubated eGFP-expressing L-forms with the fluorescent dye SynapseRed C2M (SynapseRed). Given that SynapseRed cannot diffuse through the cell membrane, any fluorescent signal on the membranes surrounding internal vesicles would be a strong argument that such vesicles were derived from the cell membrane. Indeed, SynapseRed was found to not only stain the cell membrane of the L-forms but also the membranes of internal vesicles after overnight incubation (Figure 2B). Staining with SYTO-9 further indicated that chromosomal DNA was present in the cytosol but not inside internal vesicles (Figure S2B). Incubation of protoplasts

160 producing cytosolic eGFP with Synapse Red showed that areas with less cytosolic fluorescence emission were caused by internal membrane structures rather than by formation of internal vesicles (Figure S2C). Similar incubation of S-cells showed the presence of internal vesiclelike structures. However, unlike for L-forms, subsequent staining of S-cells of a strain producing cytosolic-mCherry with SYTO-9 indicated that these vesicles were filled with chromosomal DNA. This indicates that internal structures observed in protoplasts and S-cells are not the same internal vesicles as those seen in L-forms and may not be involved uptake of external fluids. Taken together, these results strongly suggest that the observed vesicles inside become trapped inside such vesicles. 
In eukaryotes, endocytosis is a process that enables the uptake of external cargo via internal vesicle formation, which is eventually degraded or recycled (Cossart and Helenius, 2014; Elkin et al., 2016). Fluorescently labelled dextrans are widely used as markers for endocytosis in eukaryotes (Araki et al., 1996; Li et al., 2015). To identify if such an endocytosis-like process could be present in L-forms and to visualize the uptake of external materials, we incubated the cells with Dextran Texas-Red (D-TR) and performed time-lapse imaging. The L-form strain used also expresses DivIVA-eGFP, which has strong affinity for negatively curved membrane regions (alpha pKR2) (Hammond et al., 2019; Jurasek et al., 2020). Such regions are expected to be formed upon invagination of the membrane. After 290

180 minutes of incubation, D-TR was visible inside the L-form and faint spots of DivIVA-eGFP 181 started to appear adjacent to this region (Figure 2C and Video S1). This progressed to a clear inward bulging of the cell membrane with two foci of DivIVA-eGFP on either side of the invaginated membrane and an inflow of D-TR ( $\mathrm{t}=560 \mathrm{~min})$. After $640 \mathrm{~min}$ an internal vesicle was formed that contained D-TR. In other cells, DivIVA-eGFP appeared to form a ring-like structure, which sometimes enveloped the invaginating membrane (Figure 2D cell 1 and 2 respectively). The presence of DivIVA near the site of invagination implies the presence of negatively curved regions in the membrane. Notably, DivIVA is not required for vesicle formation or DNA uptake, as the deletion of divIVA in alpha (alpha $\Delta$ DivIVA) had no effect on natural transformation (two-tailed independent t-test, $t(8)=0.489, P=0.638$ ) (Figure S2D),

190 and internal vesicles were still formed by this strain (Figure S2E). Furthermore, internalization

191 of D-TR was also observed in L-forms that did not express DivIVA-eGFP, indicating that uptake is not a consequence of the presence of the fusion protein (Figure S2F). Incubation of protoplasts and S-cells with D-TR up to $72 \mathrm{~h}$ did not result in D-TR encapsulation in internal

194 vesicles (Figure S2G). Altogether, these results show that the invagination of the cell 
membrane of L-forms can lead to internal vesicle formation and may represent an endocytosis-

like mechanism allowing uptake of molecules, including DNA, from the environment.

\section{Lipid nanoparticles are internalized in vesicles in an energy-dependent manner}

199 Lipid nanoparticles (LNPs) are non-viral particles that are used to deliver nucleic acids and drugs to human cells via endocytosis (Cullis and Hope, 2017). LNPs do not have a lipid bilayer structure, but consist of an electron-dense, hydrophobic core of lipids that encapsulate nucleic acids by electrostatic interactions and are surrounded by a layer of PEG-lipids (Cullis and Hope, 2017; Evers et al., 2018; Hou et al., 2021). Once the endosome acidifies the ionizable lipids become positively charged, which allows the LNP to destabilize the endosome membrane and deliver its cargo into the cell. LNPs can also be fluorescently tagged by the incorporation of fluorophore-conjugated phospholipids (Kulkarni et al., 2019). To further explore the ability of L-forms to take up external particles, the cells were incubated with rhodamine-labelled LNPs (LNP-LR, containing 18:1 Liss Rhod PE) with an average size of $125 \mathrm{~nm}$ to allow their detection inside L-forms. After addition of LNP-LR to 7-day-old L-

210 forms, clear foci could be detected inside the cells after overnight incubation, as well as 211 localization of LNPs to the cell membrane (Figure 3A and Figure S3B and S3C). When L-

212 forms were used that express eGFP in the cytosol, vesicles only contained LNPs and not eGFP, 213 strongly suggesting that the LNPs had been internalized in vesicles devoid of the cytoplasm

214 (Figure 3B, C). Importantly, internalization of LNP-LR by L-forms could be blocked by the 215 addition of sodium azide $(1,2.5$ and $10 \mathrm{mM})$ or incubation of cells at $4^{\circ} \mathrm{C}$, conditions that are commonly used to inhibit endocytosis (Atkinson et al., 2002; Hoffmann and Mendgen, 1998;

217 Sato et al., 2009; Subramanya et al., 2009). Under such conditions, the LNPs only localized to 218 the cell membrane rather than forming foci inside the cell (Figure 3D, E and Figure S3D-E). 
219 These results are consistent with an uptake process of LNPs that is energy-dependent, whereby

220 the particles are internalized by a membrane invagination process.

222 High-resolution imaging of L-forms using cryo-FIB-SEM

223 To better understand their ultrastructure and composition, the intracellular vesicles were imaged using 3D cryo-correlative light and electron microscopy (cryo-CLEM) (Figure 4A). Cryo-FIB-SEM (Focused Ion Beam - Scanning Electron Microscopy) allows the 3D high resolution imaging of L-forms and internal vesicles. The cryogenic sample preparation and imaging ensures that the L-forms are visualized in a near-to-native state (Shimoni and Muller, 1998; Studer et al., 1989).

Following high-pressure freezing, cells with putative intracellular vesicles were detected based on internal darker regions lacking cytosolic eGFP using alpha pIJ82-GFP (Figure S4). Specific L-forms (example of selection in Figure 4B, C) were imaged in detail using cryo-FIB-SEM. The reduction in cytosolic eGFP indeed matched the presence of internal vesicles as detected by FIB-SEM (Figure 4C, D, white arrow), in line with previous results

234 (Figure 2B). In addition, the composition of the cytoplasm and internal vesicle content was different, as measured using the InLens energy selective backscattered (EsB) detector which provides contrast based on the distribution of heavier elements (Figure 4E). Analysis of the pixel intensity indicated that the contrast level inside the internal vesicle was similar to the extracellular environment, whereas the cytoplasm had a higher contrast. Moreover, an overexposure experiment showed that the vesicle has the same capacity to absorb the electron dose as the medium outside, different from the rest of the cell (Figure S5A-B). These results support

241 the finding that internal vesicles contain extracellular medium and are formed via membrane 242 invagination (Figure 2C). 
Further high-resolution imaging indicated the presence of multiple internal vesicles

244 within individual cells (Figure 4F-I, Figure S5C-E). Most detected vesicles were lining the cell membrane (Figure 4G, Figure S5C-E), varied in size and membrane thickness (Figure 4H) and could even be present inside larger vesicles (Figure 4H and Figure S6D), like the previously observed secondary vesicle (Figure S2F). In addition, vesicles could be observed budding out of the cell membrane (Figure 4I). 3D reconstruction of the budding vesicles based on contour tracing revealed that these were either an extension of an internal vesicle, or remained connected to internal vesicles, forming a complex (Figure 4J-K, Figure S6A-D, Video S2 and S3).

In some cases, cells contained intracellular regions with different grey values from the rest of the cell (Figure 4Li). These regions had a size distribution of 300 to $800 \mathrm{~nm}$, did not line the cell membrane, and were surrounded by dark particles of around $25-60 \mathrm{~nm}$ in diameter (Figure 4Lii-iv). It could be possible that these dark particles are lipid bodies, compared to previous cryo-FIB-SEM observations (Spehner et al., 2020; Vidavsky et al., 2016). A potential interpretation is that the internal regions are vesicles of which the enclosing lipid membrane has partially degraded. The lipids and lipidic degradation products may have accumulated in lipid droplets that result in the observed black particles.

These results further confirm that the internal vesicles observed in K. viridifaciens Lforms contain external medium and can be formed by invagination of the cell membrane. L-

262 forms can contain multiple vesicles of varying sizes, in some cases forming clusters or 263 complexes of vesicles that can protrude out of the cell membrane. Internal vesicles may release their contents in the cell after vesicle degradation. These findings support a model for uptake of macromolecules such as DNA by engulfment, followed by release of the cargo after vesicle disruption (Figure 5). 


\section{DISCUSSION}

269 The bacterial cell wall is an important protective barrier towards the environment, providing stress resistance and enabling the selective passage of molecules. However, in recent years it

271 has become clear that under some conditions, bacteria may also thrive without this layer.

272 Prolonged exposure to environmental stresses, such as cell-wall targeting agents or a high osmotic pressure, can induce the formation of L-forms that efficiently proliferate without their cell wall (Allan et al., 2009; Ramijan et al., 2018). The consequences of such a wall-deficient bacterial lifestyle on their ability to take up DNA are largely unknown. Here we provide evidence that L-forms may take up DNA and other macromolecules via engulfment and the subsequent formation of internal vesicles (Figure 5).

278

\section{A new mechanism for HGT?}

280

Well-known mechanisms for HGT are natural transformation, transduction, and conjugation (as reviewed in Arnold et al., 2021; Thomas and Nielsen, 2005). These mechanisms require sophisticated machinery to enable transport of DNA across the cell envelope. We here show that wall-deficient cells such as protoplasts, S-cells and L-forms of $K$. viridifaciens take up DNA using PEG. Importantly, L-forms are the only wall-deficient cells that achieve natural transformation using plasmid DNA without PEG. Naturally transformable bacteria use a canonical and complex system for DNA uptake across the cell wall and cell membrane. The

287 latter step requires the DNA-binding protein ComEA and the pore-forming channel protein

288 ComEC, with homologs found across naturally transformable Gram-positive and Gramnegative species (e.g., ComE and ComA in N. gonorrhoeae). Disruption of either of these proteins typically results in a drastic reduction or even absence of transformation (Friedrich et al., 2001; Hahn et al., 1987; Inamine and Dubnau, 1995; Yeh et al., 2003). However, disruption of the likely genes for ComEA and ComEC in L-forms of $K$. viridifaciens had no effect on the 
ability to take up DNA, suggesting a mechanism independent of the canonical DNA translocation machinery.

295

\section{An endocytosis-like process in L-form bacteria}

297 Endocytosis is a fundamental and highly regulated process in eukaryotes that is involved in the uptake of nutrients, regulation of plasma membrane composition, sensing of the extracellular environment and signaling (Thottacherry et al., 2019). Invagination of the membrane and subsequent membrane scission and vesicle formation allows cells to internalize a wide array of cargo such as fluids, ligands, plasma membrane proteins and sometimes even entire bacteria.

302 Invagination is often followed by passing the cargo through the endosomal pathway and 303 lysosomal degradation (Cossart and Helenius, 2014). Specific mammalian cells can take up DNA, followed by active gene expression (Wolff et al., 1990), which potentially occurs via endocytosis, although the exact mechanism is unclear (reviewed by Budker et al., 2000; Trombone et al., 2007; Wolff and Budker, 2005).

This work shows that L-forms use an endocytosis-like mechanism for the uptake of DNA, whereby membrane invagination led to the formation of intracellular vesicles that during their formation encapsulated extracellular material (Figure 5). Via this process, not only DNA but also other macromolecules such as $3 \mathrm{kDa}$ dextran and even 125-nm lipid nanoparticles

311 were taken up, strongly suggesting that the uptake process is non-specific. Interestingly, an

312 older study also reports the uptake of fluorescent dextrans in internal vesicles of Bacillus

313 subtilis L-forms, which was proposed to occur via fluid-phase endocytosis (Oparka et al., 314 1993).

The mechanism underlying formation of intracellular vesicles in L-forms most likely

316 depends on increased membrane dynamics due to excess membrane synthesis (Mercier et al., 317 2013; Studer et al., 2016). An imbalance in the cell surface to volume ratio due to excess 
membrane synthesis can lead to internal vesicle formation in spherical E. coli and B. subtilis

319 shape mutants (Bendezu and de Boer, 2008; Mercier et al., 2013). Internal vesicles or vacuoles 320 can also be formed in enlarged protoplasts and spheroplasts (containing an outer membrane)

321 which are maintained in conditions that allow cell membrane expansion (Nishida, 2020;

322 Takahashi et al., 2020). Indeed, a lack of excess membrane production may also explain why we did not observe consistent DNA uptake in protoplasts and S-cells, both of which are unable to proliferate without their wall.

High-resolution electron microscopy imaging revealed multiple internal vesicles inside L-forms. Interestingly, the L-forms also contained regions not surrounded by a membrane but were lined with darker spots that may represent lipid bodies (Spehner et al., 2020; Vidavsky et al., 2016), possibly originating from the degradation products of the membrane of internal vesicles. This disintegration would lead to release of the cargo into the cytoplasm. In eukaryotes, escape of therapeutics from endosomal vesicles can be mediated by bacterial, viral, and chemical agents or by nanoparticles (Patel et al., 2019; Varkouhi et al., 2011). Escape mechanisms include pore formation, destabilization of the membrane, nanoparticle swelling or osmotic rupture. High sucrose levels or the proton sponge effect facilitate the influx of protons followed by chloride ion accumulation and inflow of water, leading to rupture of the vesicle (Behr, 1997; Cervia et al., 2017; Ciftci and Levy, 2001; Liang and W. Lam, 2012). Acidification of endosomes occurs via membrane-localized vacuolar ATPases (V-ATPases) that pump protons into the vesicles (Forgac, 2007). Bacteria have similar proton pumps called

338 F-ATPases on their plasma membrane and have been found on the membrane of intracellular vesicles of enlarged protoplasts (Hensel et al., 1996; Mulkidjanian et al., 2007; Takahashi et al., 2020). Considering the complexity of known escape mechanisms further research is

341 required to understand if and how internal L-form vesicles can disintegrate to release their 342 contents in the cytoplasm. 


\section{An endocytosis-like mechanism for macromolecule uptake in primordial cells}

344 L-forms have been proposed as a model to study early lifeforms due to their lack of cell wall 345 and biophysical way of proliferation (Briers et al., 2012b; Errington et al., 2016). Horizontal 346 gene transfer is thought to have played a pivotal role in the evolution of early life (Woese, 347 1998; Woese, 2000). This may have occurred in cells that did not yet evolve a cell wall, 348 allowing genetic recombination after cell fusion or lightning-triggered electroporation 349 (Errington, 2013; Kotnik, 2013), yet other mechanisms of HGT were unknown. Internal vesicles have also been observed in L-forms of other species, with varying functions and mechanisms of vesicle formation described (Han et al., 2015; Yabu, 1991) . L-forms of Listeria monocytogenes are capable of forming DNA-containing internal vesicles along the inside of the cell, which upon release become metabolically active (Briers et al., 2012a; Dell'Era et al., 2009), as well as forming internal vesicles via membrane invagination (Studer et al., 2016). Additionally, secondary invagination of the vesicle membrane itself can result in vesicles containing cytoplasm and represent viable offspring.

These examples provide additional support for the existence of bacterial endocytosis, and we therefore propose that this may reflect an ancient mechanism that has been retained in modern cells to allow shedding their cell wall when the environmental conditions require it. These examples provide additional support for the existence of bacterial endocytosis, and we therefore propose that this may reflect an ancient mechanism of how primordial cells acquired new genetic material and nutrients via engulfment.

In conclusion, our work shows that the permanent loss of the bacterial cell wall allows the uptake of DNA, dextran and $125 \mathrm{~nm}$-sized lipid nanoparticles via internal vesicle formation. The invagination of the cell membrane, likely driven by excess membrane production, leads to the engulfment of external fluids and subsequent vesicle formation. This is an energy-dependent process that has similarities to a simple form of endocytosis as seen in 
eukaryotes. Future studies are required to further understand the molecular mechanisms behind

369 this process.

370

\section{ACKNOWLEDGEMENTS}

372 R.K. and L.Z. are supported by the TARGETBIO program of the Netherlands Organization for

373 Scientific Research (NWO), grant nr. 15812. S.S. is supported by the NWA startimpulse grant

374 (Origins Centre). As part of the COFUND project oLife, D.A. acknowledges funding from the

375 European Union's Horizon 2020 research and innovation program under the Grant Agreement

376 847675. M.d.B, R.R., D.D. and A.A. are supported by an ERCAdvanced Investigator grant 377 (H2020-ERC-2017-ADV-788982-COLMIN). A.A. is also supported by the NWO

378 (VI.Veni.192.094). We thank Nico Sommerdijk (Radboudumc, Electron Microscopy Center)

379 for his contribution with high pressure freezing of the samples.

380

\section{AUTHOR CONTRIBUTIONS}

382 R.K. and S.S. carried out the experiments. L.Z., S.S. and R.K. created the plasmids and D.A

383 provided the lipid nanoparticles. A.A., M.d.B, R.R. and D.D. performed the FIB-SEM imaging and analysis. All authors contributed to the design of the experiments and discussion of the results. R.K, D.C. and A.A. wrote the manuscript with input from all authors.

387 DECLARATION OF INTERESTS

388 The authors declare no competing interests. 
FIGURE LEGENDS

Figure 1. Natural DNA Uptake of Wall-Deficient Cells Is Independent of the Competence Proteins ComEA and ComEC and Correlates with Membrane Fluidity

(A) Schematic representation of the different wall-deficient cell types of $K$. viridifaciens that can be created artificially (protoplasts) or naturally (S-cells and L-forms). PG = peptidoglycan. (B) Mycelium, protoplasts, S-cells and L-form lines alpha, M1 and delta were incubated with plasmid DNA (pRed*) for $24 \mathrm{~h}$, plated on selective medium and incubated at $30^{\circ} \mathrm{C}$ to select for transformed cells. Note that only L-forms show consistent DNA uptake.

(C) Localization of putative ComEA and ComEC genes (BOQ63_29625 and BOQ63_29630, respectively) on the chromosome of $K$. viridifaciens DSM 40239 as compared to comEC and comEA of naturally transformable Bacillus subtilis str. 168.

400

(D) Natural transformation assay of 7-day of alpha and alpha $\Delta$ comEA/EC using pFL-ssgB. ns

401 $=$ not significant $(\mathrm{n}=5$ replicates, two-tailed independent $\mathrm{t}$-test, $t(8)=1.572, P=0.155)$. Data are represented as mean \pm SD with individual data points.

(E) Natural transformation efficiency of 1-, 3- and 7-day old alpha after $24 \mathrm{~h}$ incubation with $\mathrm{pFL}-\operatorname{sg} B$. Asterisks indicate statistically significant different transformation efficiency $(\mathrm{n}=4$ replicates, one-way ANOVA, F $(2,9)=12.16$, Tukey post-hoc test, $P=.006(1-3$ day $)$ and .005 (1-7 day)). Data are represented as mean $\pm \mathrm{SD}$ with individual data points.

(F) Generalized polarization as measurement of membrane fluidity of 1-, 3- and 7-day old alpha as calculated from the shift in the fluorescence emission spectrum of the membrane dye Laurdan. Lower GP indicates a higher membrane fluidity. Data are represented as mean $\pm \mathrm{SD}$ with individual data points, $\mathrm{n}=3$. 
415 (A) Fluorescence micrograph of alpha pIJ82-GFP (cytoplasmic eGFP; green) incubated with 416 Cy-5 labelled plasmid DNA (pFL-ssgB; magenta). BF = Brightfield. Scale bar $=2 \mu \mathrm{m}$.

417 (B) Incubation of alpha pIJ82-GFP with the membrane-impermeable dye SynapseRed C2M 418 (SynapseRed; magenta), showing two z-slices of one L-form cell. BF = brightfield. Scale bar $419=2 \mu \mathrm{m}$.

420 (C) Stills of a time-lapse imaging experiment of alpha producing DivIVA-eGFP (alpha pKR2) 421 (green) incubated with $3 \mathrm{kDa}$ Dextran-Texas Red (D-TR; magenta). Arrows indicate 422 localization of DivIVA-eGFP. Scale bar $=2 \mu \mathrm{m}$. See also Video S1.

423 (D) Formation of foci and ring-structures of DivIVA-eGFP in alpha pKR2 (green) incubated 424 with Dextran-Texas Red (D-TR, magenta). Scale bar $=2 \mu \mathrm{m}$. Note that L-forms are able to take 425 up fluorescently stained DNA and Dextran by formation of internal vesicles.

Figure 3. Localization of Lipid Nanoparticles in Internal L-form Vesicles

(A-B) Localization of LNP-LR (Lipid Nanoparticle containing 18:1 Liss Rhod PE; magenta) in internal vesicles of alpha (A) and alpha pIJ82-GFP (B) after overnight or 3-day incubation at $30^{\circ} \mathrm{C}$ respectively. Scale bar $=2 \mu \mathrm{m}$.

(C) Density profile plot and corresponding line selection of alpha pIJ82-GFP incubated with LNP-LR showing a decrease in cytoplasmic eGFP emission correlates with an increase in LNP-

433 LR emission.

434 (D-E) Localization of LNP-LR during incubation with alpha at $4^{\circ} \mathrm{C}$ (D) or in the presence of 435 $2.5 \mathrm{mM}$ sodium azide at $30^{\circ} \mathrm{C}(\mathrm{E})$ after 0,24 and $48 \mathrm{~h}$ incubation. Similar results were obtained with 1 and $10 \mathrm{mM}$ sodium azide (data not shown). Scale bar $=5 \mu \mathrm{m}$. Note that incubation of L-forms with lipid nanoparticles (average size of $125 \mathrm{~nm}$ ) results in their localization inside internal vesicles, a process that can be inhibited by incubation at $4{ }^{\circ} \mathrm{C}$ or sodium azide. 


\section{Structure in High Resolution}

441 (A) Correlated fluorescence and electron micrographs of the frozen sample (Zen Connect 442 image). The bright green dots indicate individual cells of alpha pIJ82-GFP. A finderTOP raster 443 visible both in fluorescence and electron microscopy facilitates alignment between the two 444 imaging modules. The small squares indicate different regions of interest, imaged at higher resolution. FL: Fluorescence light

(B) Higher resolution image of one region of interest, showing many fluorescent cells.

(C) L-form depicted by white box in B, showing intracellular dark sphere $(\sim 1$ micrometer, 448 white arrow).

449 (D) SEM image (SE, Inlens) of cell in C) with white arrow indicating the internal vesicle. The $\mathrm{X}, \mathrm{Y}$ and $\mathrm{Z}$ arrows in $\mathrm{B}, \mathrm{C}$ and $\mathrm{D}$ indicate the $3 \mathrm{D}$ orientation of the imaged cell as observed in 3D FIB-SEM.

(E) Superposition of five consecutive slices (backscattered images) of cell in D). Inset: Intensity plot profile (white) of the region in white box.

454 (F-I) FIB-SEM slices showing different types of internal vesicles. (F-G) Vesicles lining the cell membrane. Asterisks indicate vesicles. $(\mathrm{H})$ Vesicle complex, note the different membrane thickness of vesicles indicated with white arrows. See also Figure S6D and Video S3. (I) Membrane protrusions as indicated with white arrow. (J-K) Analysis of the interconnected vesicles of the cell in I). (Ji-iii) Three consecutive slices showing the interaction of different vesicles. Ki-iii show higher magnification of the regions 460 in white boxes in Ji-iii, respectively). (Jiv, Kiv) 3D segmentation of Ki-iii. While some of the vesicles are intracellular, others protrude out of the cell. A complete connected vesicle structure is shown in green and is indicated by white arrows in I, Jiii and Jiv. See also Figure S6A-C and 463 Video S2. 
464 (L) Regions with different contrast are lined with black particles representing putative lipid 465 bodies. The size distribution of the black particles is between 25 to $60 \mathrm{~nm}$. Scale bars represent $466500 \mathrm{~nm}$ unless otherwise specified.

467

468 Figure 5. Proposed Model for DNA Uptake by Internal Vesicle Formation in L-forms

469 Excess membrane synthesis results in invagination of the cell membrane, leading to the 470 formation of internal vesicles in L-forms. In this process, extracellular liquid containing DNA 471 or other macromolecules is engulfed. Finally, DNA is released from internal vesicles by an 472 unknown process (indicated by dashed arrow), which may involve vesicle disruption. Image 473 created with BioRender.com.

474

475 
480 (A) (Left) Transformation plates showing absence of natural transformation upon incubation of 1-and 7-day old L-form alpha with intact or fragmented gDNA of alpha $\Delta \operatorname{ssg} B$ containing an apramycin resistance cassette. (Right) Gel electrograph of $100 \mathrm{ng}$ intact (I) or fragmented

(F) gDNA of alpha $\Delta \mathrm{s} g B$ as used in the natural transformation assay.

(B) Polyethylene glycol (PEG)-based transformation efficiency of $K$. viridifaciens mycelium, protoplasts, S-cells and L-forms using plasmid DNA (pRed*) containing an apramycin resistance gene, shown as the percentage of transformed colonies per total colony forming units. Data are represented as mean $\pm \mathrm{SD}, \mathrm{n}=3$.

(C) PEG-based transformation of alpha using unmethylated or methylated plasmid DNA (pRed*), gDNA or filter-sterilized salt-lysed cells from mutant line alpha $\Delta s s g B$.

(D) Gel electrograph of PCR products from three different PCR mixes to confirm the replacement of comEA and comEC by an apramycin resistance cassette. WT $=$ gDNA alpha; $\Delta=$ gDNA alpha $\Delta$ comEA/EC. Expected products: PCR $1 \mathrm{WT}=3676 \mathrm{bp}$, mutant $=1294 \mathrm{bp}$; PCR $2 \mathrm{WT}=1197 \mathrm{bp}$, mutant $=$ no amplification, PCR $3 \mathrm{WT}=745 \mathrm{bp}$, mutant $=$ no amplification.

(E) Generalized Polarization (GP) as measure of membrane fluidity of $K$. viridifaciens protoplasts, 1-, 3- and 7- day old L-form alpha. Lower GP indicates higher fluidity. * ** and *** indicate $P \leq 0.05,0.01$ and 0.001 , respectively (one-way ANOVA, F $(3,8)=19.49$, Tukey post-hoc test, $n=3$ ). Data are represented as mean $\pm S D$ with individual data points, $n=3$.

(F) Membrane fluidity of L-form alpha (1- and 7-day old), S-cells and protoplasts of $K$. viridifaciens. Top rows show brightfield images and heatmap of fluorescence emission (red to 
blue colour indicate GP values of -1.0 to 1.0 respectively) of representative cells stained with

502 a Laurdan dye for quantifying the membrane fluidity $(\mathrm{BF}=$ brightfield, $\mathrm{FL}=$ fluorescence

503 emission). Bottom panel shows frequency distributions of the Generalized Polarization (GP).

504 Lower GP values correspond to higher membrane fluidity indicating that L-forms have more

505 fluid membranes compared to S-cells and protoplasts. Control = cells imaged and analysed 506 without Laurdan staining.

507

508

Figure S2. Analysis of DNA Content, Internal Vesicles and Uptake of D-TR of Cell-Wall

\section{Deficient Cells, and effect of $\operatorname{divIVA}$ deletion on DNA Uptake, Related to Figure 2}

510 (A) alpha pIJ82-GFP incubated without Cy-5 DNA as fluorescence control.

511 (B) alpha and alpha pRed* stained with SYTO-9 (green) to indicate chromosomal DNA. alpha

512 is stained with SynapseRed C2M (SynapseRed; magenta) to visualize cell membranes, whereas

513 (absence of) cytosolic mCherry for alpha pRed* (magenta) indicates the presence of an internal 514 vesicle.

515 (C) Protoplasts and S-cells of K. viridifaciens pIJ82-GFP producing cytosolic eGFP incubated

516 with SynapseRed for $72 \mathrm{~h}$ (top rows), and S-cells of $K$. viridifaciens $\mathrm{pRed} *$ producing cytosolic 517 mCherry incubated with SynapseRed (SR) and SYTO-9 for $72 \mathrm{~h}$ (bottom row). Chromosomal

518 DNA is visualized using SYTO-9 staining. Note that presence of internal membrane structures 519 causes a reduction in cytosolic fluorescence emission.

520 (D) Natural transformation assay of 7-day old alpha and alpha $\Delta$ divIVA using pFL-ssgB. ns $=$ 521 not significant (two-tailed independent t-test, $t(8)=0.489, P=0.638$ ). Data are represented as 522 mean $\pm \mathrm{SD}$ with individual data points, $\mathrm{n}=5$.

523 (E) L-forms without DivIVA can produce internal vesicles as shown for 5-day old 524 alpha $\Delta$ divIVA pIJ82-GFP producing cytosolic eGFP. Scale bar $=2 \mu \mathrm{m}$. 
525 (F) alpha incubated with (example 1 and 2) or without (control) Dextran Texas-Red (D-TR;

526

527

528

529

530

531

532

533

534

535

536

537 magenta), showing the formation of internal vesicles filled with D-TR. The arrow indicates the presence of a non-fluorescent secondary internal vesicle inside an existing internal vesicle (example 2). Scale bar $=5 \mu \mathrm{m}$.

(G) Protoplasts and S-cells of K. viridifaciens pIJ82-GFP incubated with D-TR for $72 \mathrm{~h}$. Note that no internalization of D-TR was observed.

\section{Figure S3. Uptake of LNP-LR by alpha, Related to Figure 3}

(A) alpha pIJ82-GFP incubated without LNP-LR (LNP-Liss Rhod; magenta) as imaging control.

(B-C) alpha incubated with (B) or without (C) LNP-LR showing localization of LNP-LR after $0 \mathrm{~h}, 24 \mathrm{~h}$ and $48 \mathrm{~h}$ or examples of autofluorescence, respectively.

(D-E) alpha incubated with PBS at 4 degrees (D) or with PBS at $30^{\circ} \mathrm{C}$ in the presence of 2.5 $\mathrm{mM}$ sodium azide $(\mathrm{E})$ as control for fluorescence emission. Images were obtained after 0, 24 and $48 \mathrm{~h}$ incubation.

\section{Figure S4. High Resolution Cryo-Fluorescence of L-forms, Related to Figure 4}

alpha pIJ82-GFP imaged using cryo-fluorescence microscopy. Putative vesicles are indicated with arrows. Images were captured using the long distance 100x objective.

\section{Figure S5. Over-dose experiment of L-form Cell using FIB-SEM, Related to Figure 4}

(A-B) FIB-SEM slice of over-dose experiment using alpha pIJ82-GFP. The yellow colour in B) indicates areas with distinguished beam damage. The vesicle (black asterisk in the center of the cell) seems to be less to none affected by the dose, similar to the medium outside the cell (black asterisk outside of the cell). The image in Figure 4D is taken before this experiment, 
550 and Figure 4E is obtained by summing several slices deeper in the cell after acquiring this 551 image.

552 (C-E) FIB-SEM slices of two cells (C-D correspond to the cell in Figure 4F and E corresponds 553 to the cell in Figure $4 \mathrm{H}-\mathrm{K}$ ), white arrows indicate vesicles that line the cell membrane. Scale 554 bar in C-E is $0.5 \mu \mathrm{m}$.

555

556 Figure S6. 3D Segmentation of L-form Vesicles, Related to Figure 4

557 (A-C) FIB-SEM slices corresponding to Figure 4I, Jiv and Ki-iii, respectively. Colours 558 correspond to the segmented colours in Figure 4Kiv. Vesicles that are budding out the cells are 559 connected to other vesicles or are elongated inside the cell. Scale bar $=200 \mathrm{~nm}$. See also Video $560 \quad$ S2

561 (D) FIB-SEM slices corresponding to the cell in Figure 4H. Z-number indicates the slice. 562 Colours indicate individual vesicles. See also Video S3. 


\section{MATERIALS AND METHODS}

\section{Bacterial strains and culture conditions}

565 The bacterial strains and plasmids used in this study are listed in Table S2 and S3 respectively.

566 Kitasatospora viridifaciens DSM40239 (Ramijan et al., 2017) was grown confluently on

567 maltose-yeast extract medium (MYM) to obtain spores, which were harvested after 3-4 days

568 of growth (Stuttard, 1982). For mycelial growth in liquid, strains were grown at a density of 1

$569 \times 10^{6}$ spores $\mathrm{ml}^{-1}$ for two days in LPB medium without sucrose at $100 \mathrm{rpm}$, while LPB with

570 sucrose was used to induce the formation of S-cells (Ramijan et al., 2018). L-forms were grown

571 on solid L-phase medium agar (LPMA) or liquid LPB medium (Ramijan et al., 2018). Liquid

572 cultures were inoculated with spores for K. viridifaciens strains or with a frozen aliquot of a 1-

573 2-day old L-form culture in case of L-form strains. L-forms were grown in liquid culture for 574 3-4 days for chemical transformation and 7 days for all other experiments unless stated specifically. L-forms were adjusted to $5-7.5 \times 10^{7} \mathrm{CFU} \mathrm{ml}^{-1}$ for transformation assays (based on $\mathrm{OD}_{600}$ of 3 for 3 - and 7-day old cells and 0.2 for 1-day old cells), and 2.5-5 x $10^{7} \mathrm{CFU} \mathrm{ml}^{-1}$ $\left(\mathrm{OD}_{600}\right.$ of 2) for all other experiments with 7-day old cells. All Kitasatospora cultures were grown at $30^{\circ} \mathrm{C}$.

Escherichia coli strains were grown on solid or liquid LB medium (while shaking at $250 \mathrm{rpm})$ at $37^{\circ} \mathrm{C}$. Where necessary, antibiotics $\left(100 \mu \mathrm{g} \mathrm{ml} l^{-1}\right.$ ampicillin, $25 \mu \mathrm{g} \mathrm{m} l^{-1}$ chloramphenicol, $5 \mu \mathrm{g} \mathrm{ml}^{-1}$ thiostrepton, $50 \mu \mathrm{g} \mathrm{ml}^{-1}$ apramycin, $100 \mu \mathrm{g} \mathrm{ml}^{-1}$ hygromycin B with the exception of $200 \mu \mathrm{g} \mathrm{ml}^{-1}$ hygromycin B for LB medium) were added to the culture medium. E. coli JM109 (Yanisch-Perron et al., 1985) was used for cloning purposes, while $E$. coli ET12567/pUZ8002 (MacNeil et al., 1992) was used to obtain methylation-deficient DNA. 


\section{Construction of plasmids}

588 All PCRs were performed using PFU or Q5 ${ }^{\circledR}$ High-Fidelity DNA polymerase (NEB). The 589 primers used in this study are listed in Table S4. To create pFL-ssgB (Table S3), a hygromycin 590 resistance cassette was amplified using primer pair Hyg_F-231_EEV and Hyg_R+1237_HEV 591 with pMS82 (Gregory et al., 2003) as the template. The PCR products were digested with 592 EcoRV and cloned into pWHM3-oriT (Wu et al., 2019) to generate pWHM3-oriT-hyg (Table 593 S3). The 3' flank of $\operatorname{ssg} B$ was digested from pKR1 (Ramijan et al., 2018) and cloned into pWHM3-oriT-hyg using XbaI and HindIII to generate the final plasmid. pRK1 (Table S3) was created by amplifying the upstream flanking region of comEA by PCR with primers FL1-comEA/comEC-FW and FL1-comEA/comEC-REV, thereby 597 introducing unique EcoRI and $\mathrm{XbaI}$ resitricion sites, while the downstream flanking region of 598 comEC, made by gene synthesis (Baseclear, Leiden, the Netherlands) was flanked by XbaI and HindIII sites. The flanking regions and apramycin cassette were cloned in pWHM3-oriT using 600 the EcoRI, HindIII restriction sites interspersed with an apramycin resistance cassette 601 containing flanking XbaI sites, thereby creating the final plasmid. The comEA/comEC deletion 602 mutant was created in L-form strain alpha (Ramijan et al., 2018) using pRK1, which replaced 603 the nucleotides +58 relative to the startcodon of comEA (BOQ63_29625) until +2489 relative to the startcodon of comEC (BOQ63_29630) with an apramycin resistance cassette. Note that the gene annotation of Streptomyces viridifaciens ATTC11989 (accession CP023698) was used to determine the putative correct start and stop codons for comEC. amplified from plasmid pGreen (Zacchetti et al., 2016) using primer pair gap1_FW_BglII and generate the final plasmid. 


\section{Construction of bacterial strains}

613 To create new strains, transformation of L-form alpha with plasmid DNA was achieved using

614 chemical transformation based on polyethylene glycol (PEG) (Kieser et al., 2000). Plasmid 615 DNA was isolated from Escherichia coli ET12567/pUZ8002 to obtain methylation-deficient 616 DNA. L-form strains alpha pIJ82-GFP and alphasdivIVA pIJ82-GFP were created using 617 chemical transformation of alpha and alpha $\Delta$ divIVA with pIJ82-GFP respectively, followed 618 by selection with hygromycin B (Table S2). The strains were verified using the detection of 619 fluorescent eGFP production using fluorescence microscopy. Strain alpha $\Delta c o m E A / E C$ was 620 obtained by chemical transformation of alpha with pRK1 followed by selection for apramycin 621 (Table S2). Subsequent growth on non-selective medium allowed for double homologous recombination leading to replacement of the $\operatorname{com} E A / E C$ region by an apramycin resistance cassette, leading to thiostrepton-sensitive, apramycin-resistant cells. The strain was verified by PCR using primer pair ComEA_Apra_check_FW and ComEC_Apra_check_RV to confirm replacement of the region by the apramycin cassette. To further confirm deletion of this region,

626 PCR was performed using primer pairs ComEC_Presence_Check_1_FW/RV and 627 ComEC_Presence_Check_2_FW/RV, which amplify parts of comEC only if this genomic 628 region is still present.

\section{Genomic DNA preparation}

631 Genomic DNA was isolated from a 5-day old culture of alpha $\Delta s \operatorname{sg} B$ (Ramijan et al., 2018) 632 using phenol:chloroform extraction (Kieser et al., 2000). Briefly, the cell pellet was resuspended in $10.3 \%$ sucrose containing $0.01 \mathrm{M}$ ethylenediamine tetraacetic acid (EDTA)

634 pH8 following lysis with $10 \%$ sodium dodecyl sulfate (SDS). Extraction with 635 phenol:chloroform was performed and the nucleic acids were precipitated using isopropanol. 636 The pellet was dissolved in Tris-EDTA buffer followed by RNase A (Thermo Fisher) and 
637 Proteinase K treatment (Qiagen). The gDNA was isolated using phenol:chloroform extraction 638 and precipitated using absolute ethanol, before resuspension in nuclease-free water. 639 Fragmented gDNA was obtained by beat-beating the intact gDNA for 12 minutes using $2 \mathrm{~mm}$ 640 diameter glass beads in a Mikro-Dismembrator U (Sartorius) at $2000 \mathrm{rpm}$. Chromosomal DNA 641 concentrations were verified using the Quant-IT ${ }^{\mathrm{TM}}$ Broad-Range dsDNA Assay Kit 642 (Invitrogen).

\section{Preparation of protoplasts from Kitasatospora}

K. viridifaciens strain DSM40239 was inoculated at a density of $5 \times 10^{6}$ spores $\mathrm{ml}^{-1}$ in TSBS:YEME (1:1) liquid medium with $0.5 \%$ (w/v) glycine and $5 \mathrm{mM} \mathrm{MgCl}_{2}$. The culture was grown for $48 \mathrm{~h}$ while shaking at $200 \mathrm{rpm}$, after which protoplasts were prepared as described (Kieser et al., 2000). Cultures of $72 \mathrm{~h}$ were used for K. viridifaciens pIJ82-GFP and pRed*. Lysozyme treatment was performed by the addition of $10 \mathrm{mg} \mathrm{ml}^{-1}$ of chicken egg-white lysozyme (Sigma $70000 \mathrm{U} \mathrm{mg}^{-1}$ ) to the mycelial suspension. The cells were incubated for 2-3 $\mathrm{h}$ at $100 \mathrm{rpm}$ and $30^{\circ} \mathrm{C}$, after which mycelial fragments were separated from the protoplasts by filtration trough a cotton wool filter (Kieser et al., 2000).

\section{Isolation of S-cells from Kitasatospora}

S-cells were isolated from LPB cultures by filtration (Ramijan et al., 2018). In short, the culture was filtered through a sterile EcoCloth ${ }^{\mathrm{TM}}$ filter (Contec) and subsequently passed through a 5 $\mu \mathrm{m}$ Isopore ${ }^{\mathrm{TM}}$ membrane filter. The cells were concentrated by gentle centrifugation at 1000 xg for 20 minutes, after which $90 \%$ of the supernatant was removed. The cell pellet was suspended carefully in the remaining liquid.

660 


\section{Chemical transformation}

663 Polyethylene-glycol (PEG) was used for transformation as described (Kieser et al., 2000),

664 using freshly prepared protoplasts, S-cells or L-forms that were kept on ice prior to 665 transformation. For chemical transformation, $50 \mu 1$ of cells were mixed with $1 \mu \mathrm{g}$ pRed* 666 (Zacchetti et al., 2018), $150 \mathrm{ng}$ gDNA of strain alpha $\Delta \operatorname{sg} B$, filter-sterilized salt-lysed cells (35 667 ng DNA from alpha $\Delta s s$ B) or MilliQ. Then, $200 \mu \mathrm{l}$ of 25\% (w/v) PEG1000 in P-buffer (Kieser 668 et al., 2000) was added to the cells, followed by gently mixing and diluting the suspension in 669 P-buffer. Serial dilutions were plated on LPMA medium and after 16-18 $\mathrm{h}$ incubation an 670 overlay was performed with $1 \mathrm{ml}$ of P-buffer containing antibiotics. Colony forming units 671 (CFU) were counted after 7 and 14 days for L-forms and S-cells/protoplasts, respectively.

672 Transformants were verified by streaking on selective medium and microscopy.

673

674 Natural transformation assay

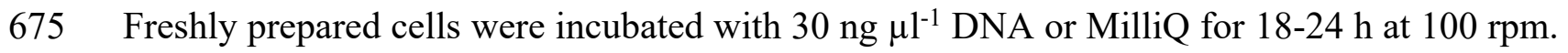
676 A final concentration of 100 and $10 \mathrm{ng} \mu \mathrm{l}^{-1}$ intact gDNA and $10 \mathrm{ng} \mathrm{ul}^{-1}$ for fragmented gDNA 677 isolated from alpha $\Delta s s g B$ was used in combination with both 1- and 7-day old alpha. Dilutions 678 were plated on selective and nonselective LPMA after careful resuspension. Colony forming 679 units were determined after 7-day incubation at $30^{\circ} \mathrm{C}$ for L-forms and mycelium and up to 14 680 days for protoplasts and S-cells. Transformants were verified by growth on selective medium 681 and by PCR (using primers Tsr_Hyg_FW1 and Tsr_Hyg_RV1) or microscopy. Cells were 682 prepared from at least five replica cultures to compare transformation efficiencies between 683 strains.

684

685 
687 Three replicate cultures of 1, 3 and 7-day old L-forms or freshly prepared protoplasts were 688 subjected to a Laurdan dye assay as a measure for membrane fluidity (Scheinpflug et al., 2017). $6891 \mathrm{ml}$ of each culture was first centrifuged at $1000 \mathrm{xg}$ for 10 minutes to remove any traces of 690 the culture media. Cells were resuspended in $1 \mathrm{ml} \mathrm{P}$-buffer and adjusted to an $\mathrm{OD}_{600}$ of 0.6 .10 mM Laurdan (6-Dodecanoyl-2-Dimethylaminonapthalene) stock solution (Invitrogen) was prepared in $100 \%$ dimethylformamide (DMF) and stored at $-20^{\circ} \mathrm{C}$ in an amber tube. To each 1 ml OD-adjusted culture, $1 \mu 1$ of Laurdan dye was added to a final concentration of $10 \mu \mathrm{M}$. The

694 cultures were then incubated in the dark at $30^{\circ} \mathrm{C}$ for $10 \mathrm{~min}$, while shaking at $100 \mathrm{rpm}$. The 695 cells were washed three times with P-buffer containing 1\% dimethyl sulfoxide to remove unbound dye molecules before the cells were resuspended in P-buffer. $200 \mu 1$ of this resuspended culture was aliquoted into a 96-well black/clear glass bottom sensoplate (Greiner Bio-one VWR). Four technical replicas were measured per culture, as well as one replica per culture condition without dye to measure background fluorescence.

Sample excitation was performed at $350 \mathrm{~nm}$ followed by fluorescence emission capture at 435 and $490 \mathrm{~nm}$, determined using a Spark ${ }^{\circledR}$ multimode microplate reader (Tecan). After subtracting the background fluorescence, the generalized polarization (GP) value was calculated using -

$$
\mathrm{GP}=\frac{\mathrm{I}_{435}-\mathrm{I}_{490}}{\mathrm{I}_{435}+\mathrm{I}_{490}}
$$

Values obtained after calculation lie in the range of -1 to +1 with those closer to -1 indicating greater fluidity.

Preparation of cells for quantification of membrane fluidity by microscopy was performed as following. Cells were washed and OD-adjusted as mentioned above. Laurdan dye 
$\mu \mathrm{M}$. The culture was placed in $30^{\circ} \mathrm{C}$ for $5 \mathrm{~min}$, while shaking at $100 \mathrm{rpm}$ in the dark. $900 \mu \mathrm{l}$ of

711 prewarmed P-buffer containing 1\% dimethyl sulfoxide was added and the culture was

712 centrifuged $(1000 \mathrm{xg}, 10 \mathrm{~min})$ to remove any unbound dye molecules. The cells were finally

713 resuspended in $100 \mu 1$ of P-buffer for microscopy analysis. Cells treated similarly but without

714 Laurdan dye were used a control for microscopy measurements.

715

716

\section{Preparation of fluorescently labelled DNA}

717 Fluorescently labelled plasmid DNA was prepared using The Mirus Label $\mathrm{IT}^{\circledR} \mathrm{Cy}^{\mathrm{TM}} 5$ Labelling 718 Kit according to the manufacturer's specifications. Aliquots of labelled DNA (100 ng $\left.\mu \mathrm{l}^{-1}\right)$ 719 were stored at $-20^{\circ} \mathrm{C}$ until further use.

\section{Self-assembly of lipid nanoparticles}

All lipids (DLin-MC3-DMA/Cholesterol/DSPC/DMG-PEG2k/18:1 Liss Rhod PE) were combined in a molar ratio of 50/38.3/10/1.5/0.2 using stock solutions $(100 \mu \mathrm{M}-10 \mathrm{mM})$ in chloroform:methanol (1:1). Organic solvents were evaporated under a nitrogen stream and remaining solvent was removed in vacuo for at least $1 \mathrm{~h}$. Subsequently, the lipid film was dissolved in $\mathrm{EtOH}_{\mathrm{abs}}$ and a $50 \mathrm{mM}$ citrate buffer $(\mathrm{pH}=4$, MilliQ) was prepared. Each solution was loaded into separate syringes and connected to a T-junction microfluidic mixer. The solutions were mixed in a 3:1 flow ratio of citrate buffer against lipids $\left(1.5 \mathrm{~mL} \mathrm{~min}^{-1}\right.$ for citrate buffer, $0.5 \mathrm{~mL} \mathrm{~min} \mathrm{~m}^{-1}$ for lipid solutions) giving a total lipid concentration of $1 \mathrm{mM}$. After mixing, the solution was directly loaded in a 10k MWCO dialysis cassette (Slide-A-Lyzer ${ }^{\mathrm{TM}}$, Thermo Scientific) and dialyzed against 1x Phosphate Buffered Saline (PBS, $137 \mathrm{mM} \mathrm{NaCl}$, performed with cells resuspended in LPB of which the final volume of LNP solution was 25\%. 


\section{Hydrodynamic diameter and zeta-potential measurement}

736 Dynamic light scattering (DLS) measurements were performed on a Zetasizer Nano Series

737 (Malvern Instruments, Malvern, UK). The incorporated HeNe laser works at a wavelength of $738633 \mathrm{~nm}$ and uses a detector at an angle of $173^{\circ}$ (noninvasive back scatter technology). 739 Measurements were recorded with 1 min equilibration time in UV cuvettes at $25^{\circ} \mathrm{C}$. For the estimation of z-average diameter (intensity weight mean diameter) and polydispersity index

741 (PDI)(relative width of particle size distribution) samples were prepared by tenfold dilution with $1 \mathrm{x}$ PBS. For the estimation of the zeta potential the sample was diluted with $0.1 \mathrm{x}$ Phosphate Buffered Saline (13.7 mM NaCl, $0.27 \mathrm{mM} \mathrm{KCl,} 0.8 \mathrm{mM} \mathrm{Na}_{2} \mathrm{HPO}_{4}$, and $0.2 \mathrm{mM}$ $\mathrm{KH}_{2} \mathrm{PO}_{4}$ ). All the data were in triplicates to obtain the mean value.

\section{Fluorescence and light microscopy}

747 Detection of fluorescence emission of transformants was performed using a Zeiss Axioscope A.1 equipped with a Zeiss Axiocam 305 color digital camera, using filter set 63 HE (Carl Zeiss, consisting of a $572 / 25 \mathrm{~nm}$ bandpass excitation filter, $590 \mathrm{~nm}$ beamsplitter and 629/62 nm

750 bandpass emission filter) to capture mCherry fluorescence. All other microscopy was performed using a Zeiss LSM 900 confocal microscope with Airyscan 2 module, temperature control chamber and Zen 3.1 software (blue edition, Carl Zeiss Microscopy GmbH). All excitation and emission settings for this microscope are listed in Table S5. Multichannel (DIC and fluorescence) and multistack images were obtained unless specified otherwise. $10 \mu \mathrm{l}$ of cells were imaged on an 8 -chamber slide (ibidi ${ }^{\circledR}$ ) coated with $0.1 \%$ poly-L-lysine (excess polyL-lysine was removed and the slide was allowed to dry prior to applying the sample). For timelapse imaging or overnight incubation in the temperature control chamber, $400 \mu \mathrm{l}$ of cell culture added to a $35 \mathrm{~mm}$ imaging $\mu$-Dish (ibidi ${ }^{\circledR}$ ) and allowed to settle at $30^{\circ} \mathrm{C}$ for an hour 
before overnight imaging. Image analysis was performed using Fiji (ImageJ) software

760 (Schindelin et al., 2012).

Chromosomal DNA was visualized after incubation for 30 min with SYTO-9 at a final concentration of $2 \mu \mathrm{M}$. Cell membranes were visualized by incubation with SynapseRed C2M (SynapseRed) (PromoKine, PromoCell GmbH) at a final concentration of $0.2 \mu \mathrm{g} \mathrm{ml}^{-1}$. After overnight incubation in a $\mu$-Dish (ibidi ${ }^{\circledR}$ ) using the Zeiss LSM 900 confocal temperature control chamber, cells were imaged using the Airyscan mode with super resolution post-image processing via the Zen software. Protoplasts and S-cells were incubated with SynapseRed up to $72 \mathrm{~h}$ before imaging on a glass slide.

Uptake of fluorescently labelled DNA was assessed by incubating cells with Cy-5 labelled plasmid DNA (pFL-ssgB) at a final concentration of $1.25 \mu \mathrm{g} \mathrm{ml}^{-1}$ and was imaged after 48 h.

To capture internal vesicle formation and uptake of Dextran-Texas Red (D-TR), cells of alpha pKR2 were incubated with a final concentration of $1 \mathrm{mg} \mathrm{ml}^{-1}$ Dextran-Texas Red (3000 MW, neutral, Molecular Probes) in PBS and were imaged overnight. Multistack imaging across $6 \mu \mathrm{m}$ total distance with $1.5 \mu \mathrm{m}$ steps was done with an image captured every 10 minutes. Uptake of D-TR in alpha, protoplasts or S-cells was assessed after incubation up to $72 \mathrm{~h}$.

Uptake of red fluorescent LNPs (LNP-LR) by alpha was visualized by imaging after overnight incubation in a $\mu$-Dish (ibidi ${ }^{\circledR}$ ) or after incubation for up to three days prior to imaging as indicated. Inhibition of LNP uptake was performed by incubation in the presence of 1-, 2.5- or 10-mM sodium azide (Sigma) or incubation at $4{ }^{\circ} \mathrm{C}$, and images were obtained using via the Zen software after 0,24 and $48 \mathrm{~h}$. To determine the subcellular localization of LNP-LR in alpha pIJ82-GFP, imaging was performed using the Airyscan mode with super 
783

784

785

786

787

788

789

790

791

792

793

794

795

796

797

798

799

800

801

802

803

804

805

806

resolution post-image processing and analyzed using the pixel intensity of the red (LNP-LR) and green (eGFP) channels using the Plot Profile tool in Fiji (ImageJ).

To measure the membrane fluidity, samples were excited using a $405 \mathrm{~nm}$ laser and images were captured at emissions of $430 \mathrm{~nm}$ and $500 \mathrm{~nm}$. GP value was calculated using the 'Calculate GP' plug-in in Fiji (Vischer, 2016) to obtain a histogram of pixel counts over the range of -1 to +1 . Briefly, the image is split into individual channels followed by background subtraction and setting the non-significant pixels to zero. The images are then assigned letters "A" and "B" to calculate A-B and A+B using the image calculator. Finally, a ratio of (A$\mathrm{B}) /(\mathrm{A}+\mathrm{B})$ is shown as an image where minimum pixel values are set to -1 (red) and maximum pixel values set to +1 (blue). Using the analyze histogram function a list of values is obtained and used for plotting the distributions of different samples.

\section{Cryo-correlative fluorescence and electron microscopy}

High pressure freezing

7-day old L-form stain alpha pIJ82-GFP expressing cytoplasmic eGFP was adjusted to $\mathrm{OD}_{600}$ of 2 in fresh medium containing 25\% (v/v) PBS and a final concentration of $17 \%$ sucrose. Cells were incubated for four days, during which cells settled to the bottom. A few microliters of the resuspended L-form pellet was sandwiched between HPF (High-Pressure-Freezing) carriers with $2 \mathrm{~mm}$ internal diameter (either $0.1 \mathrm{~mm}$ or $0.05 \mathrm{~mm}$ cavity, Art. 241 and Art. 390 respectively, Wohlwend) and tailor-made grid labeled, flat-sided finderTOP (Alu-platelet labelled, $0.3 \mathrm{~mm}$, Art.1644 Wohlwend) to allow an imprint of a finder matrix on the amorphous ice (de Beer et al., 2021). The finderTOP was treated with 1\% L- $\alpha$-phosphatidylcholine (61755, Sigma) in ethanol (1.00983.1000, Supelco) before freezing. The samples were then high pressure frozen (Live $\mu$, CryoCapCell) and stored in liquid nitrogen until imaging. 
807 To improve correlation between cryo-light and cryo electron microscopy, the frozen samples

808 were loaded into a universal cryo-holder (Art. 349559-8100-020, Zeiss cryo accessory kit)

809 using the ZEISS Correlative Cryo Workflow solution, fit into the PrepDek ${ }^{\circledR}$ (PP3010Z,

810 Quorum technologies, Laughton, UK). Here, the HPF carriers fits into a universal cryo-holder,

811 which subsequently can be placed into an adaptor specific for cryo-light or cryo-electron

812 microscopy.

813

814 Cryo-fluorescence imaging to detect regions of interests (ROI)

815 The frozen samples were imaged with a cryo-stage adaptor (CMS-196, Linkam scientific inc.)

816 applied to an upright confocal microscope (LSM900, Zeiss microscopy GmbH) equipped with

817 an Airyscan 2 detector. Overview images (Zeiss C Epiplan-Apochromat 5x/0.2 DIC) were

818 made with reflection microscopy to visualize the gridded pattern on the ice surface. Next,

819 medium-resolution Z-stack images (Zeiss C Epiplan-Apochromat 10x/0.4 DIC) were taken

820 with a $488 \mathrm{~nm}$ laser $(0.4 \%)$ with a voxel size of $0.15 \mu \mathrm{m} \times 0.15 \mu \mathrm{m} \times 1.18 \mu \mathrm{m}$. Using this

821 resolution, cells of interest could be selected and Z-stack images were created (Zeiss C Epiplan-

822 Neofluar 100x/0.75 DIC) using a $488 \mathrm{~nm}$ laser (4\%), with a voxel size of $0.08 \mu \mathrm{m} \times 0.08 \mu \mathrm{m}$

$823 \times 0.44 \mu \mathrm{m}$. In addition, the ice surface was imaged in all ROIs with reflection microscopy for

824 correlation purposes in the FIB-SEM.

825 Prior to cryo-light imaging, a Zeiss ZEN Connect project (Zeiss software for correlative

826 microscopy, version 3.1) was created to make a working sheet (canvas) to align and overlay all

827 the images and to facilitate further correlation with cryo-FIB-SEM.

828

829

3D Cryo-FIB-SEM

830 The sample was sputter-coated with platinum, $5 \mathrm{~mA}$ current for 30 seconds, using the prep stage

831 sputter coater (PP3010, Quorum technologies, Laughton, England) and was transferred into the 

the PP3010T preparation chamber (Quorum, Laughton, England). Throughout imaging, the

834 samples were kept at $-140^{\circ} \mathrm{C}$ and the system vacuum pressure was $1 \times 10^{-6}$ mbar.

835 After inserting the sample into the FIB-SEM chamber, overview images were taken using the 836 SEM to align the data with the LSM reflection image of the surface of the same ZEN Connect 837 project. This alignment enables the stage registration which allows using the fluorescence 838 signal to navigate to different regions of interest. After initial alignment using the SEM, a FIB 839 image of the surface was collected with the $30 \mathrm{kV} @ 10 \mathrm{pA}$ probe in $54^{\circ}$ tilt.

841 A coarse trench was milled for SEM observation using the 30 kV@30 nA FIB probe. Cold deposition was done with platinum for $30 \mathrm{sec}$. Fine FIB milling on the cross section was done using the 30kV@700pA probe. For serial FIB milling and SEM imaging the slice (trench) width was $40 \mu \mathrm{m}$ and for FIB milling the $30 \mathrm{kV} @ 300 \mathrm{pA}$ probe was used, with a slice thickness of $20 \mathrm{~nm}$. When a new slice surface was exposed by FIB milling, an InLens secondary and EsB

846 images were simultaneously collected at $2.33 \mathrm{kV}$ acceleration potential with $250 \mathrm{pA}$ probe current. The EsB grid was set to -928 V. The image size was set to $2048 \times 1536$ pixels. For noise reduction line average with a line average count $\mathrm{N}=46$ at scan speed 1 was used. The voxel size of all stacks was $5 \times 5 \times 20 \mathrm{~nm}^{3}$.

850

3D FIB-SEM Image post processing

852 The cryo-FIB-SEM images were processed using MATLAB (R2018b, Natick, Massachusetts:

853 The MathWorks Inc.) to correct for defects such as curtaining, misalignment and local 854 charging. The same software was used for subsequent noise reduction and contrast 855 enhancement. A summary of each processing step is as follows: 
856 Curtaining: Removing the vertical stripes in the stacks was done following a wavelet-FFT

857 filtering approach described by (Munch et al., 2009). In brief, the high frequency information

858 corresponding to the vertical stripes was successively condensed into a single coefficient map 859 using decomposition by "coif" wavelet family. Subsequently, a 2D-fourier transform was

860 performed to further tighten the stripe information into narrow bands. Finally, the condensed 861 stipe information was eliminated by multiplication with a gaussian damping function and the 862 destriped image was reconstructed by inverse wavelet transform.

Alignment: The consecutive slices were aligned using normalized cross correlation. Briefly,

864 the first image in the stack was chosen as reference and the second image was translated pixel

865 by pixel across the reference and a normalized cross correlation matrix was obtained using the 866 "normxcorr2" function. The location of the highest peak in the cross-correlation matrix 867 (representing the best correlation) was then used to calculate the translation required to align the two images. Once the moving image was aligned with the reference image, it served as the 869 reference for alignment of the subsequent slice.

870 Charging: Elimination of the local charge imbalance was achieved using anisotropic gaussian 871 background subtraction. Briefly, the "imgaussfilt" function was used to perform 2D-gaussian smoothing with a two-element standard deviation vector. The elements in the vector were chosen in a manner to apply a broad and sharp gaussian in the horizontal and vertical directions,

874 respectively. Subsequently, the corrected image was obtained by subtracting the filtered image 875 from the original image.

876 Noise Reduction: In order to improve the signal-to-noise ratio, noise reduction was performed 877 using anisotropic diffusion filtering (Perona and Malik, 1990). Briefly, using the "imdiffuseest" 878 function, the optimal gradient threshold and number of iterations required to filter each image 879 was estimated. Subsequently, the "imdiffusefilt" function was applied with the estimated 880 optimal parameter values to denoise each image. 
881 Contrast enhancement: As the final processing step, the contrast was enhanced using "Contrast-

882 limited adaptive histogram equalization" (Zuiderveld, 1994). Using the "adapthisteq" function,

883 the contrast was enhanced in two steps, using a uniform distribution and a low clipping limit

884 in order to avoid over-amplification of homogeneous regions.

885 3D segmentation: DragonflyTM image analysis and deep-learning software (version 2021.1,

886 Objects Research Systems, Montreal, QC, Canada) was used to segment all image data.

887

888 Bioinformatic search for putative competence genes

889 Protein sequences from Bacillus subtilis str. 168, Neisseria gonorrhoeae and Helicobacter 890 pylori strain P12 were obtained from the UniProt database or literature (Wolfgang et al., 1999).

891 These sequences were used for a BlastP search against the non-redundant protein sequence 892 database of Streptomyces viridifaciens (taxid 48665). Hits belonging to Streptomyces 893 viridifaciens strain DSM40239, sequence accession numbers CP090840 to CP090842 with an 894 E-value of $1 \times 10^{-6}$ or lower were collected (Table S1).

895

\section{Statistics}

897 All statistics were performed using SPSS statistics software (IBM, version 27.0). P-values less 898 than 0.05 were considered statistically significant.

899

900 
902 Video S1. Uptake of Dextran-Texas Red by L-forms, Related to Figure 2

903 Timelapse video of alpha-DivIVA-eGFP (green) incubated with 3 kDa Dextran-Texas Red (D-

904 TR; magenta). Left: Brightfield. Right: Composite of green and magenta channels. Scale bar 905 indicates $1 \mu \mathrm{m}$.

906

907 Video S2. 3D Reconstruction of Vesicles in L-form Cell, Related to Figure 4

908 3D segmentation of alpha pIJ82-GFP corresponding to Figure 4 Jiv and Kiv. Colours indicate

909 individual vesicles or vesicle complexes. The cell is depicted in grey.

910

911 Video S3. 3D Reconstruction of Vesicles in L-form Cell, Related to Figure 4

912 3D segmentation of alpha pIJ82-GFP corresponding to Figure 4H and Figure S6D. Colours

913 indicate individual vesicles or vesicle complexes. The cell is depicted in grey. 


\section{REFERENCES}

Allan, E.J., Hoischen, C., and Gumpert, J. (2009). Bacterial L-forms. Adv Appl Microbiol 68, $1-39$.

Araki, N., Johnson, M.T., and Swanson, J.A. (1996). A role for phosphoinositide 3-kinase in the completion of macropinocytosis and phagocytosis by macrophages. Journal of Cell Biology $135,1249-1260$.

Arnold, B.J., Huang, I.T., and Hanage, W.P. (2021). Horizontal gene transfer and adaptive evolution in bacteria. Nat Rev Microbiol.

Atkinson, H.A., Daniels, A., and Read, N.D. (2002). Live-cell imaging of endocytosis during conidial germination in the rice blast fungus, Magnaporthe grisea. Fungal Genetics and Biology 37, 233-244.

Behr, J.-P. (1997). The proton sponge: a trick to enter cells the viruses did not exploit. CHIMIA International Journal for Chemistry 51, 34-36.

Bendezu, F.O., and de Boer, P.A. (2008). Conditional lethality, division defects, membrane involution, and endocytosis in mre and mrd shape mutants of Escherichia coli. J Bacteriol 190, 1792-1811.

Bierman, M., Logan, R., O'Brien, K., Seno, E.T., Rao, R.N., and Schoner, B.E. (1992). Plasmid cloning vectors for the conjugal transfer of DNA from Escherichia coli to Streptomyces spp. Gene 116, 43-49.

Briers, Y., Staubli, T., Schmid, M.C., Wagner, M., Schuppler, M., and Loessner, M.J. (2012a). Intracellular vesicles as reproduction elements in cell wall-deficient L-form bacteria. PLoS One 7, e38514.

Briers, Y., Walde, P., Schuppler, M., and Loessner, M.J. (2012b). How did bacterial ancestors reproduce? Lessons from L-form cells and giant lipid vesicles: multiplication similarities between lipid vesicles and L-form bacteria. Bioessays 34, 1078-1084.

Budker, V., Budker, T., Zhang, G., Subbotin, V., Loomis, A., and Wolff, J.A. (2000). Hypothesis: naked plasmid DNA is taken up by cells in vivo by a receptor-mediated process. The journal of gene medicine 2, 76-88.

Cervia, L.D., Chang, C.C., Wang, L., and Yuan, F. (2017). Distinct effects of endosomal escape and inhibition of endosomal trafficking on gene delivery via electrotransfection. PLoS One 12, e0171699.

Chapman, D. (1975). Phase transitions and fluidity characteristics of lipids and cell membranes. Quarterly reviews of biophysics 8, 185-235.

Chen, I., and Dubnau, D. (2004). DNA uptake during bacterial transformation. Nat Rev Microbiol 2, 241-249.

Ciftci, K., and Levy, R.J. (2001). Enhanced plasmid DNA transfection with lysosomotropic agents in cultured fibroblasts. International journal of pharmaceutics 218, 81-92.

Cossart, P., and Helenius, A. (2014). Endocytosis of viruses and bacteria. Cold Spring Harb Perspect Biol 6.

Costa, T.R., Felisberto-Rodrigues, C., Meir, A., Prevost, M.S., Redzej, A., Trokter, M., and Waksman, G. (2015). Secretion systems in Gram-negative bacteria: structural and mechanistic insights. Nat Rev Microbiol 13, 343-359.

Cullis, P.R., and Hope, M.J. (2017). Lipid Nanoparticle Systems for Enabling Gene Therapies. Mol Ther 25, 1467-1475.

de Beer, M., Roverts, R., Heiligenstein, X., Lamers, E., Sommerdijk, N., and Akiva, A. (2021). Visualizing Biological Tissues: A Multiscale Workflow from Live Imaging to 3D CryoCLEM. Microscopy and Microanalysis 27, 11-12. 
962 Dell'Era, S., Buchrieser, C., Couve, E., Schnell, B., Briers, Y., Schuppler, M., and Loessner, 963 M.J. (2009). Listeria monocytogenes L-forms respond to cell wall deficiency by modifying gene expression and the mode of division. Mol Microbiol 73, 306-322.

965

966 Dubnau, D. (1991). Genetic competence in Bacillus subtilis. Microbiological reviews 55, 395424.

967

Elkin, S.R., Lakoduk, A.M., and Schmid, S.L. (2016). Endocytic pathways and endosomal trafficking: a primer. Wien Med Wochenschr 166, 196-204. Ellison, C.K., Dalia, T.N., Vidal Ceballos, A., Wang, J.C., Biais, N., Brun, Y.V., and Dalia, A.B. (2018). Retraction of DNA-bound type IV competence pili initiates DNA uptake during natural transformation in Vibrio cholerae. Nat Microbiol 3, 773-780. Errington, J. (2013). L-form bacteria, cell walls and the origins of life. Open Biol 3, 120143. Errington, J., Mickiewicz, K., Kawai, Y., and Wu, L.J. (2016). L-form bacteria, chronic diseases and the origins of life. Phil Trans R Soc B 371, 20150494. Evers, M.J.W., Kulkarni, J.A., van der Meel, R., Cullis, P.R., Vader, P., and Schiffelers, R.M. (2018). State-of-the-Art Design and Rapid-Mixing Production Techniques of Lipid Nanoparticles for Nucleic Acid Delivery. Small Methods 2.

978 Forgac, M. (2007). Vacuolar ATPases: rotary proton pumps in physiology and pathophysiology. Nat Rev Mol Cell Biol 8, 917-929.

980 Forster, B.M., and Marquis, H. (2012). Protein transport across the cell wall of monoderm 981 Gram-positive bacteria. Mol Microbiol 84, 405-413.

982 Friedrich, A., Hartsch, T., and Averhoff, B. (2001). Natural transformation in mesophilic and 983 thermophilic bacteria: identification and characterization of novel, closely related competence 984 genes in Acinetobacter sp. strain BD413 and Thermus thermophilus HB27. Applied and Environmental Microbiology 67, 3140-3148.

Gilbreath, J.J., Cody, W.L., Merrell, D.S., and Hendrixson, D.R. (2011). Change is good: variations in common biological mechanisms in the epsilonproteobacterial genera Campylobacter and Helicobacter. Microbiol Mol Biol Rev 75, 84-132.

Gregory, M.A., Till, R., and Smith, M.C.M. (2003). Integration site for Streptomyces phage phiBT1 and development of site-specific integrating vectors. J Bacteriol 185, 5320-5323.

Hahn, J., Albano, M., and Dubnau, D. (1987). Isolation and characterization of Tn917lacgenerated competence mutants of Bacillus subtilis. J Bacteriol 169, 3104-3109.

993 Hammond, L.R., White, M.L., and Eswara, P.J. (2019). ¡vIVA la DivIVA! J Bacteriol 201.

994 Hamoen, L.W., Venema, G., and Kuipers, O.P. (2003). Controlling competence in Bacillus subtilis: shared use of regulators. Microbiology (Reading) 149, 9-17.

Han, J., Shi, W., Xu, X., Wang, S., Zhang, S., He, L., Sun, X., and Zhang, Y. (2015). Conditions and mutations affecting Staphylococcus aureus L-form formation. Microbiology 161, 57-66. Hensel, M., Achmus, H., DeckersHebestreit, G., and Altendorf, K. (1996). The ATP synthase of Streptomyces lividans: Characterization and purification of the F1Fo complex. Bba1000 Bioenergetics 1274, 101-108.

1001 Hoffmann, J., and Mendgen, K. (1998). Endocytosis and membrane turnover in the germ tube 1002 of uromyces fabae. Fungal Genet Biol 24, 77-85.

1003 Hou, X.C., Zaks, T., Langer, R., and Dong, Y.Z. (2021). Lipid nanoparticles for mRNA 1004 delivery. Nat Rev Mater 6, 1078-1094.

1005 Inamine, G.S., and Dubnau, D. (1995). ComEA, a Bacillus subtilis integral membrane protein 1006 required for genetic transformation, is needed for both DNA binding and transport. J Bacteriol $1007 \quad 177,3045-3051$.

1008 Jurasek, M., Flardh, K., and Vacha, R. (2020). Effect of membrane composition on DivIVAmembrane interaction. Biochim Biophys Acta Biomembr 1862, 183144.

Kieser, T., Bibb, M.J., Buttner, M.J., Chater, K.F., and Hopwood, D.A. (2000). Practical Streptomyces genetics (Norwich: The John Innes Foundation). 
1012 Kotnik, T. (2013). Lightning-triggered electroporation and electrofusion as possible 1013 contributors to natural horizontal gene transfer. Phys Life Rev 10, 351-370.

1014 Kruger, N.J., and Stingl, K. (2011). Two steps away from novelty--principles of bacterial DNA 1015 uptake. Mol Microbiol 80, 860-867.

1016 Kulkarni, J.A., Witzigmann, D., Chen, S., Cullis, P.R., and van der Meel, R. (2019). Lipid 1017 Nanoparticle Technology for Clinical Translation of siRNA Therapeutics. Accounts Chem Res 1018 52, 2435-2444.

1019 Lande, M.B., Donovan, J.M., and Zeidel, M.L. (1995). The relationship between membrane 1020 fluidity and permeabilities to water, solutes, ammonia, and protons. J Gen Physiol 106, 67-84. 1021 Lenaz, G. (1987). Lipid fluidity and membrane protein dynamics. Biosci Rep 7, 823-837.

1022 Li, L., Wan, T., Wan, M., Liu, B., Cheng, R., and Zhang, R. (2015). The effect of the size of 1023 fluorescent dextran on its endocytic pathway. Cell Biol Int 39, 531-539.

1024 Liang, W., and W. Lam, J.K. (2012). Endosomal Escape Pathways for Non-Viral Nucleic Acid Delivery Systems. In Molecular Regulation of Endocytosis.

MacNeil, D.J., Gewain, K.M., Ruby, C.L., Dezeny, G., Gibbons, P.H., and MacNeil, T. (1992). Analysis of Streptomyces avermitilis genes required for avermectin biosynthesis utilizing a novel integration vector. Gene 111, 61-68.

Mercier, R., Kawai, Y., and Errington, J. (2013). Excess membrane synthesis drives a primitive mode of cell proliferation. Cell 152, 997-1007.

Mulkidjanian, A.Y., Makarova, K.S., Galperin, M.Y., and Koonin, E.V. (2007). Inventing the dynamo machine: the evolution of the F-type and V-type ATPases. Nat Rev Microbiol 5, 892899.

1034 Munch, B., Trtik, P., Marone, F., and Stampanoni, M. (2009). Stripe and ring artifact removal with combined wavelet - Fourier filtering. Opt Express 17, 8567-8591.

Muschiol, S., Balaban, M., Normark, S., and Henriques-Normark, B. (2015). Uptake of extracellular DNA: competence induced pili in natural transformation of Streptococcus pneumoniae. Bioessays 37, 426-435.

Nishida, H. (2020). Factors That Affect the Enlargement of Bacterial Protoplasts and Spheroplasts. Int J Mol Sci 21.

Oparka, K.J., Wright, K.M., Murant, E.A., and Allan, E.J. (1993). Fluid-Phase Endocytosis Do Plants Need It. J Exp Bot 44, 247-255.

Patel, S., Kim, J., Herrera, M., Mukherjee, A., Kabanov, A.V., and Sahay, G. (2019). Brief update on endocytosis of nanomedicines. Adv Drug Deliv Rev 144, 90-111. Perona, P., and Malik, J. (1990). Scale-Space and Edge-Detection Using Anisotropic Diffusion. Ieee T Pattern Anal 12, 629-639.

Ramijan, K., Ultee, E., Willemse, J., Zhang, Z., Wondergem, J.A.J., van der Meij, A., Heinrich, D., Briegel, A., van Wezel, G.P., and Claessen, D. (2018). Stress-induced formation of cell wall-deficient cells in filamentous actinomycetes. Nat Commun 9, 5164.

Ramijan, K., van Wezel, G.P., and Claessen, D. (2017). Genome sequence of the filamentous actinomycete Kitasatospora viridifaciens. Genome Announc 5, e01560-01516. Roberts, J., and Park, J.S. (2004). Mfd, the bacterial transcription repair coupling factor: translocation, repair and termination. Current Opinion in Microbiology 7, 120-125. Sato, K., Nagai, J., Mitsui, N., Ryoko, Y., and Takano, M. (2009). Effects of endocytosis inhibitors on internalization of human IgG by Caco-2 human intestinal epithelial cells. Life Sci 85, 800-807.

Scheinpflug, K., Krylova, O., and Strahl, H. (2017). Measurement of Cell Membrane Fluidity by Laurdan GP: Fluorescence Spectroscopy and Microscopy. Methods Mol Biol 1520, 159174. 
1060 Schindelin, J., Arganda-Carreras, I., Frise, E., Kaynig, V., Longair, M., Pietzsch, T., Preibisch, 1061 S., Rueden, C., Saalfeld, S., Schmid, B., et al. (2012). Fiji: an open-source platform for biological-image analysis. Nat Methods 9, 676-682.

Shimoni, E., and Muller, M. (1998). On optimizing high-pressure freezing: from heat transfer theory to a new microbiopsy device. J Microsc 192, 236-247.

Shitut, S., Shen, M.-J., Claushuis, B., Derks, R.J.E., Giera, M., Rozen, D., Claessen, D., and Kros, A. (2021). Generating heterokaryotic cells via bacterial cell-cell fusion. BioRxiv.

Spehner, D., Steyer, A.M., Bertinetti, L., Orlov, I., Benoit, L., Pernet-Gallay, K., Schertel, A., and Schultz, P. (2020). Cryo-FIB-SEM as a promising tool for localizing proteins in 3D. J Struct Biol 211, 107528.

1070 Studer, D., Michel, M., and Muller, M. (1989). High pressure freezing comes of age. Scanning 1071 Microscopy 3, 253-268; discussion 268.

1072 Studer, P., Staubli, T., Wieser, N., Wolf, P., Schuppler, M., and Loessner, M.J. (2016). Proliferation of Listeria monocytogenes L-form cells by formation of internal and external vesicles. Nat Commun 7, 13631.

Stülke, J., Eilers, H., and Schmidl, S.R. (2009). Mycoplasma and spiroplasma. In Encyclopedia of microbiology, M. Schaechter, ed. (Oxford: Elsevier), pp. 208-219.

Stuttard, C. (1982). Temperate phages of Streptomyces venezuelae: lysogeny and host specificity shown by phages SV1 and SV2. J Gen Microbiol 128, 115-121.

Subramanya, S., Hardin, C.F., Steverding, D., and Mensa-Wilmot, K. (2009). Glycosylphosphatidylinositol-specific phospholipase $\mathrm{C}$ regulates transferrin endocytosis in the African trypanosome. Biochem J 417, 685-694.

Takahashi, S., Mizuma, M., Kami, S., and Nishida, H. (2020). Species-dependent protoplast enlargement involves different types of vacuole generation in bacteria. Sci Rep 10, 8832.

Thomas, C.M., and Nielsen, K.M. (2005). Mechanisms of, and barriers to, horizontal gene transfer between bacteria. Nat Rev Microbiol 3, 711-721.

Thottacherry, J.J., Sathe, M., Prabhakara, C., and Mayor, S. (2019). Spoiled for Choice: Diverse Endocytic Pathways Function at the Cell Surface. Annu Rev Cell Dev Bi 35, 55-84. Trombone, A.P., Silva, C.L., Lima, K.M., Oliver, C., Jamur, M.C., Prescott, A.R., and CoelhoCastelo, A.A. (2007). Endocytosis of DNA-Hsp65 alters the pH of the late endosome/lysosome and interferes with antigen presentation. PLoS One 2, e923.

1091 Varkouhi, A.K., Scholte, M., Storm, G., and Haisma, H.J. (2011). Endosomal escape pathways 1092 for delivery of biologicals. J Control Release 151, 220-228.

1093 Vidavsky, N., Akiva, A., Kaplan-Ashiri, I., Rechav, K., Addadi, L., Weiner, S., and Schertel, A. (2016). Cryo-FIB-SEM serial milling and block face imaging: Large volume structural analysis of biological tissues preserved close to their native state. J Struct Biol 196, 487-495. Vischer, N. (2016). Using ImageJ to show "Generalized Polarization" (GP).

Woese, C. (1998). The universal ancestor. P Natl Acad Sci USA 95, 6854-6859.

1100 Wolff, J.A., and Budker, V. (2005). The Mechanism of Naked DNA Uptake and Expression. 1101 Adv Genet 54, 3-20.

1102 Wolff, J.A., Malone, R.W., Williams, P., Chong, W., Acsadi, G., Jani, A., and Felgner, P.L. (1990). Direct Gene-Transfer into Mouse Muscle Invivo. Science 247, 1465-1468.

Wolfgang, M., van Putten, J.P.M., Hayes, S.F., and Koomey, M. (1999). The comP locus of Neisseria gonorrhoeae encodes a type IV prepilin that is dispensable for pilus biogenesis but essential for natural transformation. Molecular Microbiology 31, 1345-1357.

Wu, C., van der Heul, H.U., Melnik, A.V., Lubben, J., Dorrestein, P.C., Minnaard, A.J., Choi, Y.H., and van Wezel, G.P. (2019). Lugdunomycin, an Angucycline-Derived Molecule with Unprecedented Chemical Architecture. Angew Chem Int Ed Engl 58, 2809-2814. 
1110 Yabu, K. (1991). Formation of Vesiculated Large Bodies of Staphylococcus-Aureus L-Form

1111 in a Liquid-Medium. Microbiology and Immunology 35, 395-404.

1112 Yanisch-Perron, C., Vieira, J., and Messing, J. (1985). Improved M13 phage cloning vectors 1113 and host strains: nucleotide sequences of the M13mp18 and pUC19 vectors. Gene 33, 103-119.

1114 Yeh, Y.C., Lin, T.L., Chang, K.C., and Wang, J.T. (2003). Characterization of a ComE3 1115 homologue essential for DNA transformation in Helicobacter pylori. Infect Immun 71, 542711165431.

1117 Zacchetti, B., Smits, P., and Claessen, D. (2018). Dynamics of pellet fragmentation and 1118 aggregation in liquid-grown cultures of Streptomyces lividans. Front Microbiol 9, 943.

1119 Zacchetti, B., Willemse, J., Recter, B., van Dissel, D., van Wezel, G.P., Wösten, H.A.B., and

1120 Claessen, D. (2016). Aggregation of germlings is a major contributing factor towards mycelial 1121 heterogeneity of Streptomyces. Sci Rep 6, 27045.

1122 Zhang, L., Ramijan, K., Carrion, V.J., van der Aart, L.T., Willemse, J., van Wezel, G.P., and 1123 Claessen, D. (2021). An alternative and conserved cell wall enzyme that can substitute for the 1124 lipid II synthase MurG. mBio 12.

1125 Zuiderveld, K. (1994). Contrast limited adaptive histogram equalization. Graphics gems, 474485. 
1129 SUPPLEMENTAL TABLES

1130 Table S1. BlastP results showing significant hits (E-value $<1 \mathrm{e}-06$ ), E-value and percent

1131 identity against $K$. viridifaciens DSM40239.

\begin{tabular}{|c|c|c|c|c|}
\hline Organism & Protein name & Hits & E-value & Percent identity \\
\hline Bacillus subtilis & ComEA & BOQ63_29625 & $5.28 \mathrm{e}-24$ & $34.90 \%$ \\
\hline \multirow[t]{6}{*}{ strain 168} & ComEC & BOQ63_29630 & $1.78 \mathrm{e}-09$ & $26.81 \%$ \\
\hline & ComFA & BOQ63_20315 & $1.03 \mathrm{e}-07$ & $24.83 \%$ \\
\hline & ComGA, ComGB, & - & - & \\
\hline & ComGC, ComGD, & & & \\
\hline & ComGE, ComGF, & & & \\
\hline & ComGG, ComC & & & \\
\hline Neisseria & ComE & BOQ63_29625 & $4.05 \mathrm{e}-10$ & $46.43 \%$ \\
\hline \multirow[t]{3}{*}{ gonorrhoeae } & ComA, ComP*, PilC, & - & - & \\
\hline & PilD, PilE, PilV, & & & \\
\hline & PilQ, PilF, PilG, PilT & & & \\
\hline Helicobacter & ComE3 (ComEC), & - & - & \\
\hline pylori strain $\mathrm{P} 12$ & ComB2-4, Com6-10 & & & \\
\hline
\end{tabular}

1132 *Protein sequence obtained from Wolfgang et al. (1999) 
1133 Table S2. Strains used in this study.

\begin{tabular}{|c|c|c|}
\hline Strain & Description & Notes/references \\
\hline Escherichia coli JM109 & 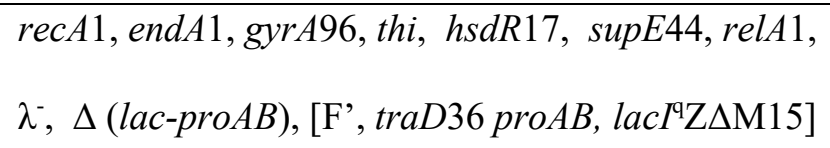 & Yanisch-Perron et al. (1985) \\
\hline $\begin{array}{l}\text { Escherichia coli } \\
\text { ET12567/pUZ8002 }\end{array}$ & $\begin{array}{l}\text { Methylation-deficient strain } \\
\left(\mathrm{F}^{-}, \text {dam-13::Tn9, dcm-6, hsdM, hsdR, recF } 143, \text { zjj- }\right. \\
202:: \operatorname{Tn} 10, \text { galK2, galT22, ara } 14, \operatorname{lac} Y 1, x y l-5 \text {, } \\
\text { leuB6, thi-1, tonA31, rpsL136, hisG4, tsx-78, mtl-1, } \\
\text { glnV44) carrying the non-transmissible pUZ8002 } \\
\text { plasmid }\end{array}$ & MacNeil et al. (1992) \\
\hline $\begin{array}{l}\text { Kitasatospora } \\
\text { viridifaciens DSM40239 }\end{array}$ & Wild-type strain & $\begin{array}{l}\text { DSMZ, Ramijan et al. } \\
(2017)\end{array}$ \\
\hline alpha & $\begin{array}{l}\text { L-form derivative of DSM40239 obtained after } \\
\text { exposure to Penicillin G and lysozyme }\end{array}$ & Ramijan et al. (2018) \\
\hline M1 & $\begin{array}{l}\text { L-form derivative of DSM40239 obtained after } \\
\text { exposure to hyperosmotic stress }\end{array}$ & Ramijan et al. (2018) \\
\hline delta & $\begin{array}{l}\text { L-form derivative of DSM40239 obtained after } \\
\text { exposure to Penicillin G and lysozyme }\end{array}$ & Shitut et al. (2021) \\
\hline alpha pIJ82-GFP & alpha containing pIJ82-GFP & This work \\
\hline alpha pKR2 & $\begin{array}{l}\text { alpha containing } \mathrm{pKR} 2 \text {, which contains a C-terminal } \\
\text { eGFP gene fusion to divIVA under the control of the } \\
\text { S. coelicolor gap1 promoter }\end{array}$ & Zhang et al. (2021) \\
\hline alpha $\triangle$ divIVA & $\operatorname{divIVA::aac(3)IV}$ & Zhang et al. (2021) \\
\hline alpha $\Delta$ divIVA $\mathrm{pIJ} 82-\mathrm{GFP}$ & alpha $\triangle$ divIVA containing pIJ82-GFP & This work \\
\hline alpha $\Delta \operatorname{ssg} B$ & $\operatorname{ssgB}:: a a c(3) I V$ & Ramijan et al. (2018) \\
\hline alpha $\Delta c o m E A / E C$ & $(\operatorname{comEA}-\operatorname{comEC}) \because \because \operatorname{aac}(3) I V$ & This work \\
\hline
\end{tabular}


1134 Table S3. Plasmids used in this study.

\begin{tabular}{|c|c|c|}
\hline Plasmid & Features & Notes/References \\
\hline pRed* & $\begin{array}{l}\text { pIJ8630-derivative expressing mCherry under } \\
\text { control of the S. coelicolor A3(2) gapl promoter }\end{array}$ & Zacchetti et al. (2018) \\
\hline pGreen & $\begin{array}{l}\text { pIJ8630-derivative expressing eGFP under control } \\
\text { of the } S \text {. coelicolor A3(2) gapl promoter }\end{array}$ & Zacchetti et al. (2016) \\
\hline pSET152 & $\begin{array}{l}\text { E. coli-Streptomyces shuttle vector; high copy } \\
\text { number in E. coli and integrating in the } \phi \mathrm{C} 31 \text { attB } \\
\text { site in Streptomyces }\end{array}$ & Bierman et al. (1992) \\
\hline pIJ82 & $\begin{array}{l}\text { pSET152-derivative carrying a hygromycin } \\
\text { resistance cassette }\end{array}$ & $\begin{array}{l}\text { Kindly provided by Dr. B. } \\
\text { Gust (JIC) }\end{array}$ \\
\hline pIJ82-GFP & $\begin{array}{l}\text { pSET152-derivative expressing eGFP under } \\
\text { control of the S. coelicolor gapl promoter }\end{array}$ & This work \\
\hline pMS82 & $\begin{array}{l}\text { E. coli-Streptomyces shuttle vector integrative in } \\
\text { the } \phi \mathrm{BT} 1 \text { att } B \text { site for genomic integration in } \\
\text { Streptomyces }\end{array}$ & Gregory et al. (2003) \\
\hline pWHM3-oriT & $\begin{array}{l}\text { Self-replicating, multi-copy, unstable plasmid } \\
\text { harboring oriT, used as E. coli/Streptomyces shuttle } \\
\text { vector }\end{array}$ & Wu et al. (2019) \\
\hline pWHM3-oriT-hyg & $\begin{array}{l}\text { pWHM3-oriT-derivative carrying a hygromycin } \\
\text { resistance cassette inserted in to the } t s r \text { gene in the } \\
\text { EcoRV site }\end{array}$ & This work \\
\hline pFL-ssg $B$ & $\begin{array}{l}\text { pWHM3-oriT-hyg-derivative containing a } \\
\text { hygromycin resistance gene and a downstream } \\
\text { flanking sequence of } \operatorname{ssg} B \text { downstream derived } \\
\text { from pKR1 to enable integration into the genome }\end{array}$ & This work \\
\hline
\end{tabular}




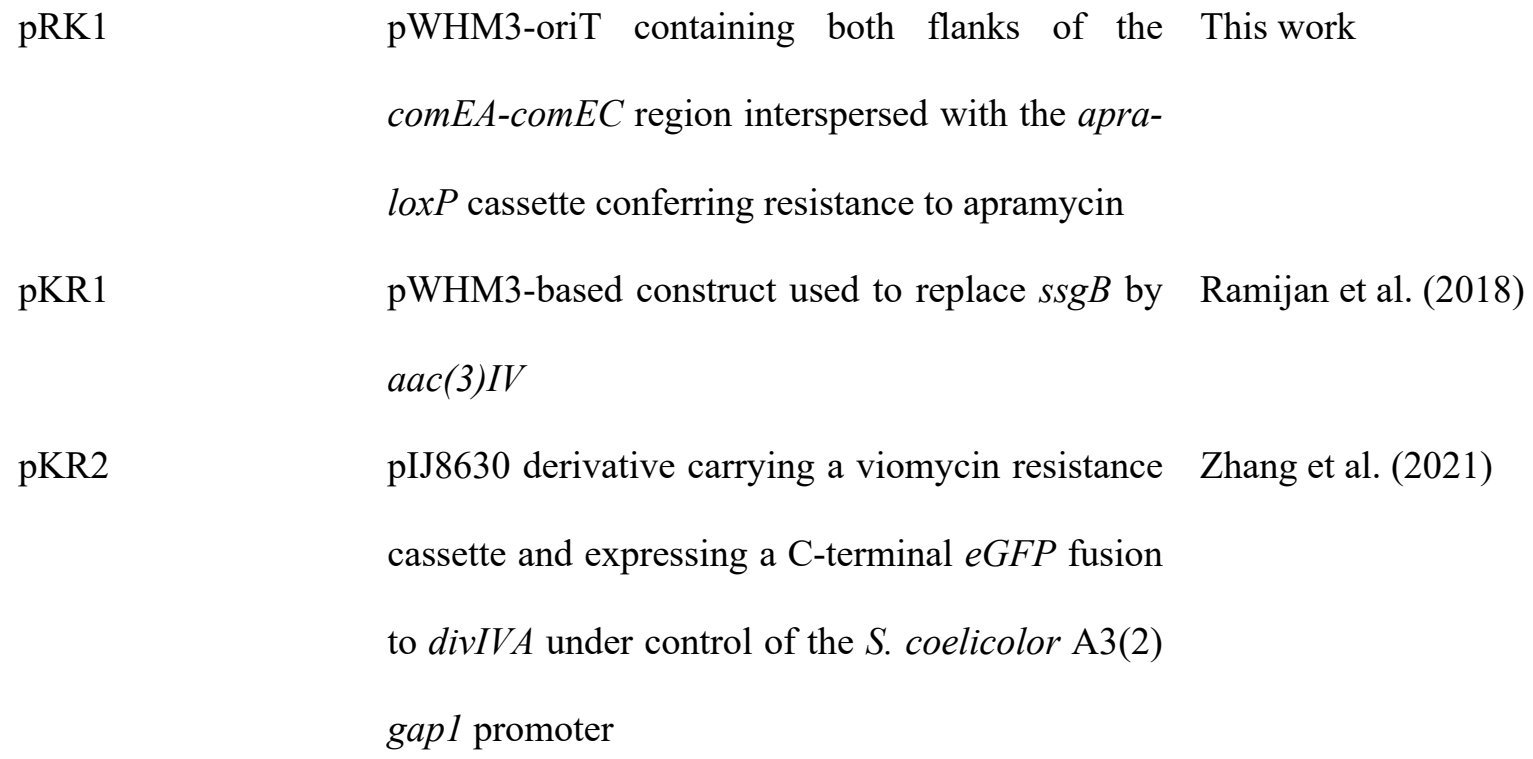

1135

1136 
1137 Table S4. Primers used in this study.

\begin{tabular}{|c|c|c|c|}
\hline Primer & Sequence (5' - 3') & Notes & Reference \\
\hline Hyg_F-231_EEV & $\begin{array}{l}\text { ctgaGAATTCGATATCGATCG } \\
\text { GCGGGGCCTGGCGGCG }\end{array}$ & $\begin{array}{l}\text { Amplification of the } \\
\text { hygromycin resistance } \\
\text { cassette from pMS82 }\end{array}$ & This work \\
\hline Hyg_R+1237_HEV & $\begin{array}{l}\text { ctgaAAGCTTGATATCGGATC } \\
\text { CTTGCCGAGCTGGGAT }\end{array}$ & $\begin{array}{l}\text { Amplification of the } \\
\text { hygromycin resistance } \\
\text { cassette from pMS } 82\end{array}$ & This work \\
\hline FL1-comEA/comEC- & GACGAATTCAGGACCGGAT & Amplification of flank 1 of & This work \\
\hline FW & GCACCGGTTC & comEA-comEC locus & \\
\hline FL1-comEA/comEC- & GAATCTAGACCGCACCGTCT & Amplification of flank 1 of & This work \\
\hline REV & CGTTGATCG & comEA-comEC locus & \\
\hline ComEA_Apra_check_ & CACTCGTGTGAGTGACCGTT & Amplification of comEA & This work \\
\hline FW & & region in PCR1 mix & \\
\hline ComEC_Apra_check_ & AACGGCAAGGGTGGACG & Amplification of comEA & This work \\
\hline RV & & region in PCR1 mix & \\
\hline ComEC_Presence_Ch & TACGACACCGAGTCCGCAG & Amplification of comEC & This work \\
\hline eck_1_FW & & region 1 in PCR2 mix & \\
\hline ComEC_Presence_Ch & CGCAAGGGCCAACATGTCTC & Amplification of comEC & This work \\
\hline eck_1_RV & & region 1 in PCR2 mix & \\
\hline ComEC_Presence_Ch & AGACCCTCCTCACCGTCAAG & Amplification of comEC & This work \\
\hline eck_2_FW & & region 2 in PCR2 mix & \\
\hline ComEC_Presence_Ch & GACAGCAGGAAACCGAAGG & Amplification of comEC & This work \\
\hline eck_2_RV & A & region 2 in PCR2 mix & \\
\hline gap1_FW_BglII & $\begin{array}{l}\text { GATTACAGATCTCCGAGGGC } \\
\text { TTCGAGACC }\end{array}$ & $\begin{array}{l}\text { Amplification of the region } \\
\text { containing the gapl promoter }\end{array}$ & This work \\
\hline
\end{tabular}




\begin{tabular}{|c|c|c|c|}
\hline egfp_RV_EcoRI & $\begin{array}{l}\text { TAAGCAGAATTCTTACTTGT } \\
\text { ACAGCTCGTCCA }\end{array}$ & $\begin{array}{l}\text { Amplification of the region } \\
\text { containing the gapl promoter } \\
\text { and } e G F P \text { gene from pGreen }\end{array}$ & This work \\
\hline SsgB_Presence_FW & $\begin{array}{l}\text { GGCGGGTACTCCGTGATGAT } \\
\text { TC }\end{array}$ & $\begin{array}{l}\text { Confirmation of } s s g B \\
\text { replacement by apra-loxP } \\
\text { cassette }\end{array}$ & This work \\
\hline SsgB_Presence_RV & AGCTTTCGGCGAGGATGTGG & $\begin{array}{l}\text { Confirmation of } s s g B \\
\text { replacement by apra-loxP } \\
\text { cassette }\end{array}$ & This work \\
\hline Tsr_Hyg_FW1 & AAGGCCAAGACATTCGGCAT & $\begin{array}{l}\text { Confirmation of presence of } \\
\text { pFL-ssgB in natural } \\
\text { transformants }\end{array}$ & This work \\
\hline Tsr_Hyg_RV1 & CGAGCGACGTGCGTACTATC & $\begin{array}{l}\text { Confirmation of presence of } \\
\text { pFL-ssgB in natural } \\
\text { transformants }\end{array}$ & This work \\
\hline
\end{tabular}


1140 Table S5. Imaging settings used with the Zeiss LSM 900 confocal microscope.

\begin{tabular}{lll}
\hline Fluorescent dye or particle & Excitation (nm) & Emission filter (nm) \\
\hline eGFP & 488 & $490-575$ \\
mCherry & 561 & $565-700$ \\
SYTO-9 & 488 & $490-575$ \\
SynapseRed C2M & 506 & $571-700$ \\
Dextran-Texas Red & 584 & $560-700$ \\
Cy5 & 650 & $450-700$ \\
LNP-LR & 587 & $565-700$ \\
\hline
\end{tabular}

1141

1142 
1143 Table S6. Dynamic Light Scattering (DLS) and $\zeta$-potential of lipid nanoparticles. PDI = 1144 polydispersity index.

1145

\begin{tabular}{cccc}
\hline LNP & $\begin{array}{c}\text { Avg. size (nm) at } \\
\mathbf{2 5}{ }^{\circ} \mathbf{C}\end{array}$ & PDI & $\begin{array}{c}\text { S-potential at 25 } \\
{ }^{\circ} \mathbf{C}\end{array}$ \\
\hline LNP-LR & 125.8 & 0.126 & -8.5 \\
\hline
\end{tabular}


Wall-deficient cells

Protoplasts

S-cells

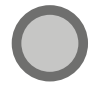

PG absent

\section{L-forms}

8<smiles></smiles>

a

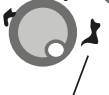

Loose PG
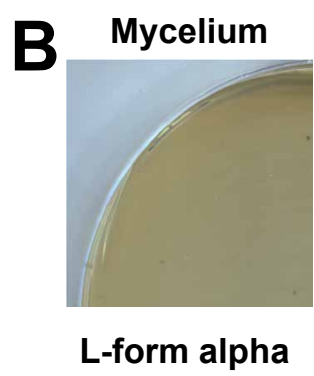

Protoplasts
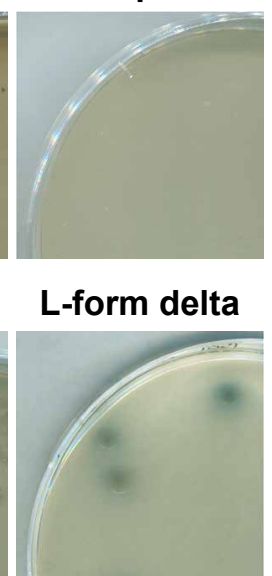

L-form M1

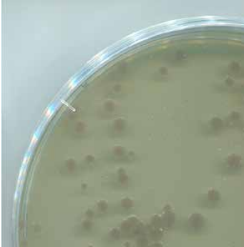

C

Bacillus subtilis str. 168

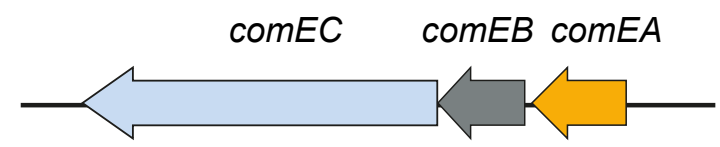

Kitasatospora viridifaciens DSM 40239

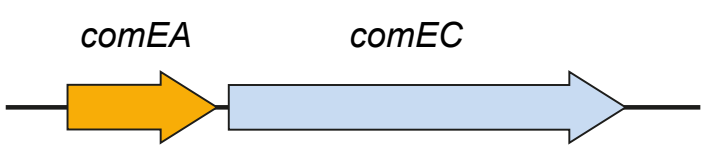

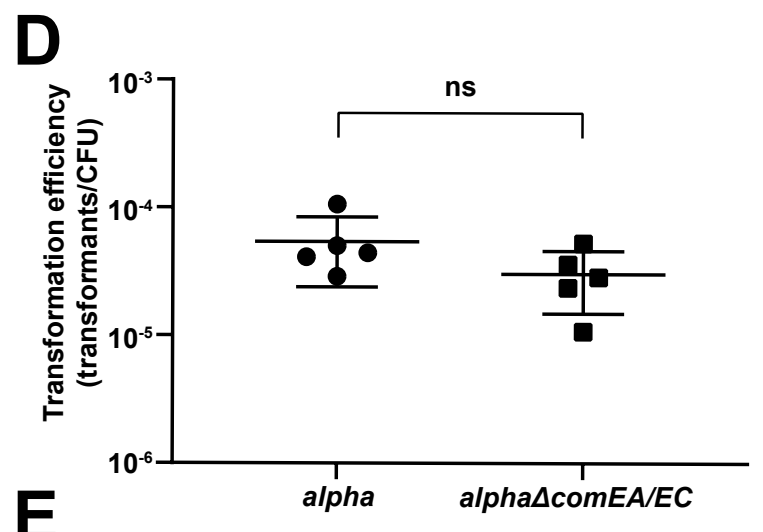
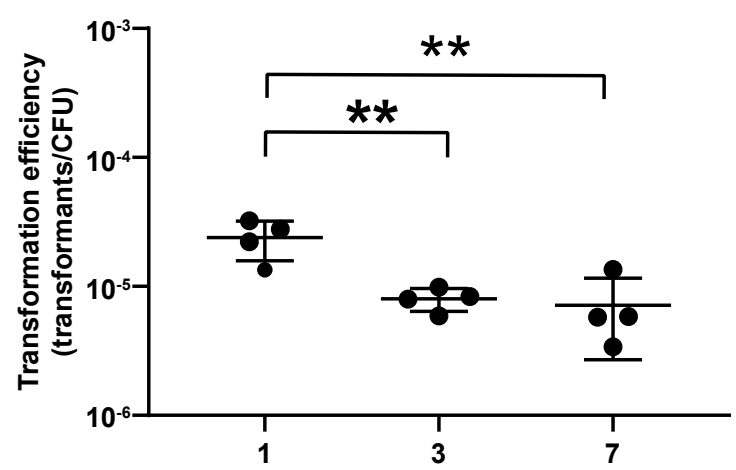

Age of culture (days)

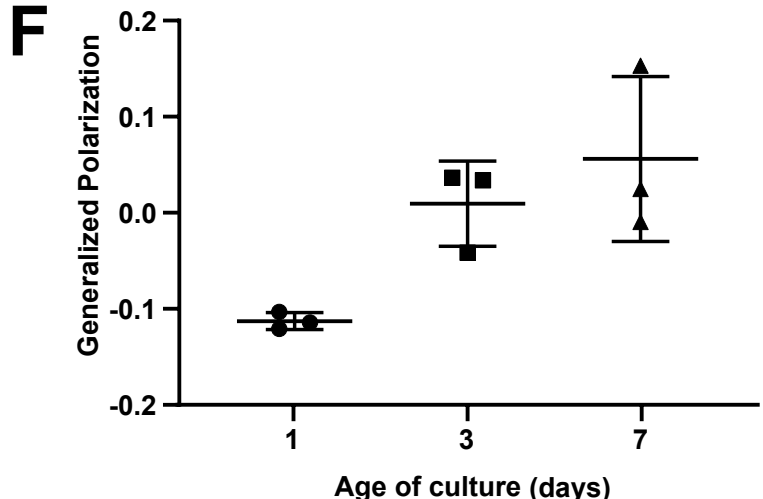

Figure 1. Natural DNA Uptake of Wall-Deficient Cells Is Independent of the Competence Proteins ComEA and ComEC and Correlates with Membrane Fluidity

(A) Schematic representation of the different wall-deficient cell types of $K$. viridifaciens that can be created artificially (protoplasts) or naturally (S-cells and L-forms). PG = peptidoglycan.

(B) Mycelium, protoplasts, S-cells and L-form lines alpha, M1 and delta were incubated with plasmid DNA (pRed*) for $24 \mathrm{~h}$, plated on selective medium and incubated at $30^{\circ} \mathrm{C}$ to select for transformed cells. Note that only L-forms show consistent DNA uptake.

(C) Localization of putative ComEA and ComEC genes (BOQ63 29625 and BOQ63 29630, respectively) on the chromosome of $K$. viridifaciens DSM 40239 as compared to comEC and comEA of naturally transformable Bacillus subtilis str. 168.

(D) Natural transformation assay of 7-day of alpha and alpha $\triangle$ comEA/EC using pFL-ssgB. ns = not significant ( $\mathrm{n}=5$ replicates, two-tailed independent $\mathrm{t}$-test, $\mathrm{t}(8)=1.572, \mathrm{P}=0.155)$. Data are represented as mean $\pm \mathrm{SD}$ with individual data points.

(E) Natural transformation efficiency of 1-, 3- and 7-day old alpha after $24 \mathrm{~h}$ incubation with pFL-ssgB. Asterisks indicate statistically significant different transformation efficiency $(\mathrm{n}=4$ replicates, one-way ANOVA, $\mathrm{F}(2,9)=$ 12.16, Tukey post-hoc test, $\mathrm{P}=.006$ (1-3 day) and .005 (1-7 day)). Data are represented as mean $\pm \mathrm{SD}$ with individual data points.

(F) Generalized polarization as measurement of membrane fluidity of 1-, 3- and 7-day old alpha as calculated from the shift in the fluorescence emission spectrum of the membrane dye Laurdan. Lower GP indicates a higher membrane fluidity. Data are represented as mean \pm SD with individual data points, $n=3$. 

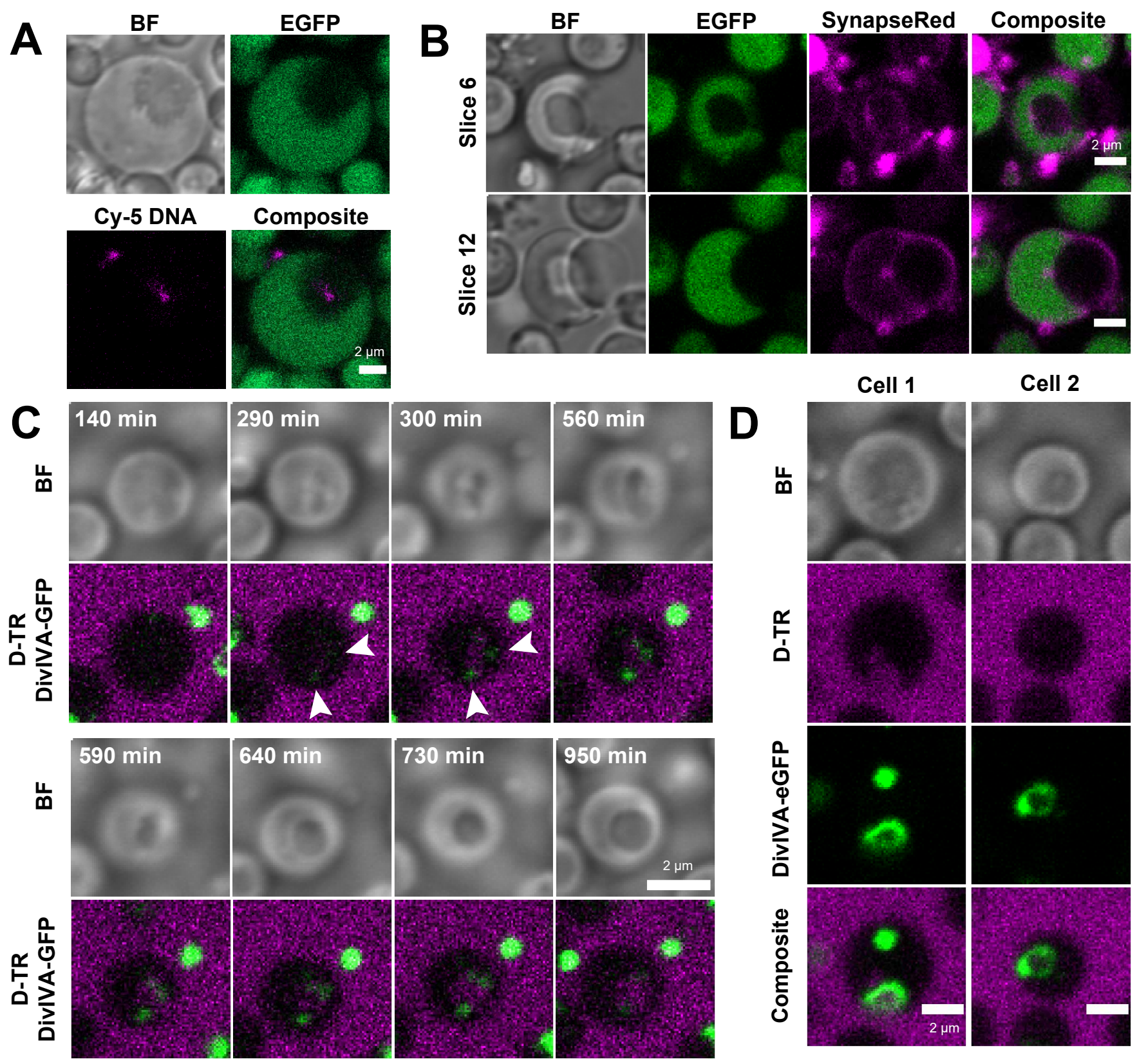

Figure 2. Formation of Internal Vesicles and Uptake of External Fluids in L-forms

(A) Fluorescence micrograph of alpha pIJ82-GFP (cytoplasmic eGFP; green) incubated with Cy-5 labelled plasmid DNA (pFL-ssgB; magenta). BF $=$ Brightfield. Scale bar $=2 \mu \mathrm{m}$.

(B) Incubation of alpha pIJ82-GFP with the membrane-impermeable dye SynapseRed C2M (SynapseRed; magenta), showing two $\mathrm{z}$-slices of one L-form cell. $\mathrm{BF}=$ brightfield. Scale bar $=2 \mu \mathrm{m}$.

(C) Stills of a time-lapse imaging experiment of alpha producing DivIVA-eGFP (alpha pKR2) (green) incubated with $3 \mathrm{kDa}$ Dextran-Texas Red (D-TR; magenta). Arrows indicate localization of DivIVA-eGFP. Scale bar $=2 \mu \mathrm{m}$. See also Video S1.

(D) Formation of foci and ring-structures of DivIVA-eGFP in alpha pKR2 (green) incubated with Dextran-Texas Red (D-TR, magenta). Scale bar $=2 \mu \mathrm{m}$. Note that L-forms are able to take up fluorescently stained DNA and Dextran by formation of internal vesicles. 


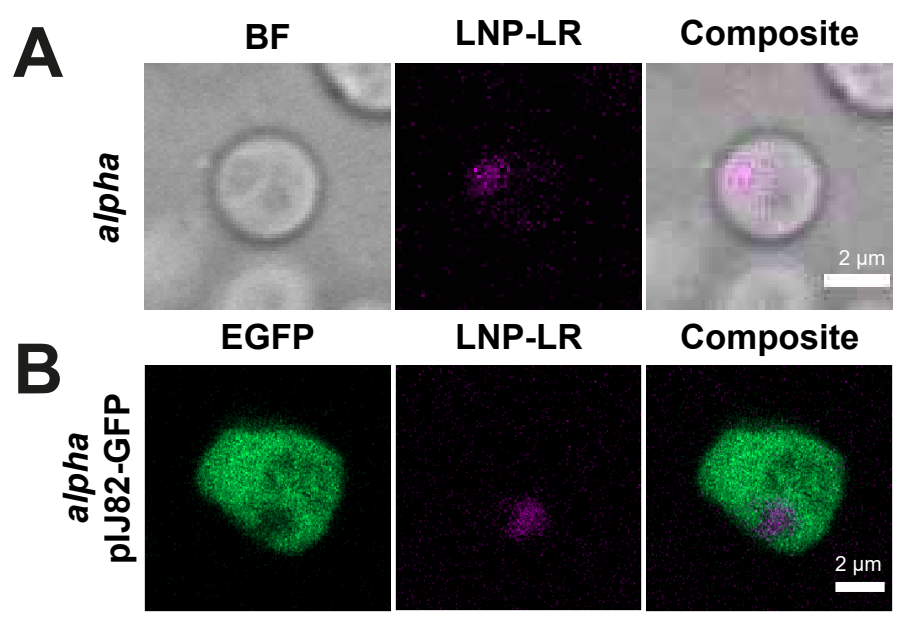

D

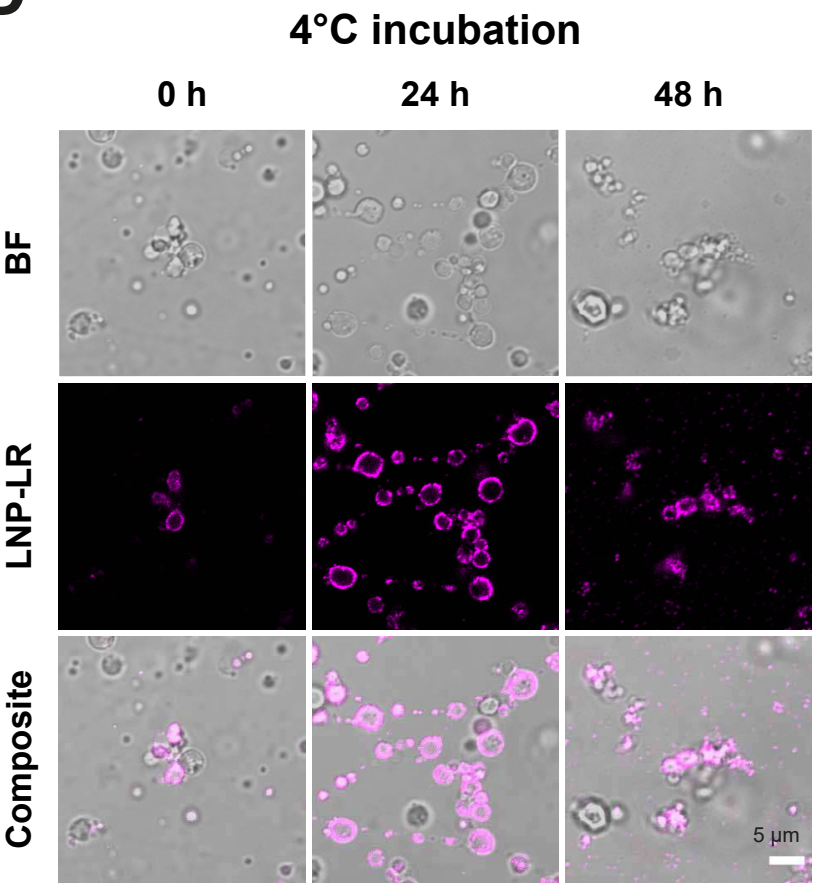

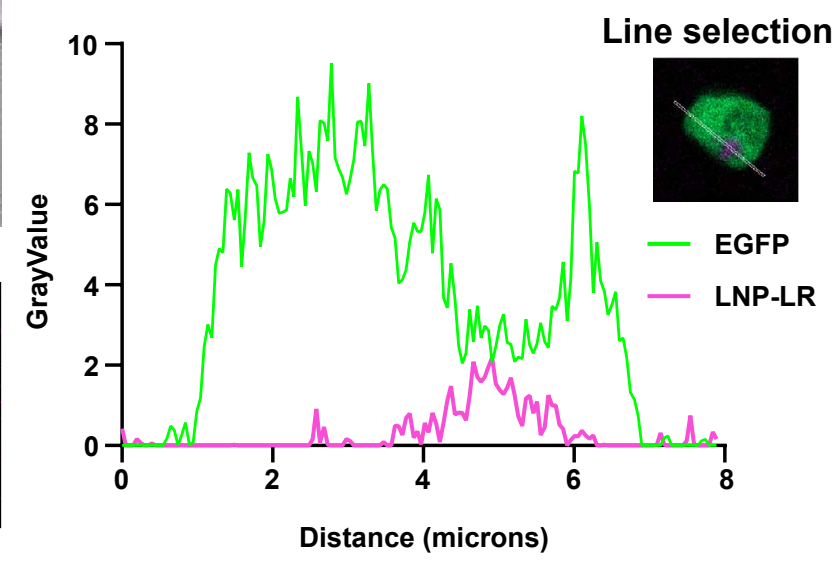

$2.5 \mathrm{mM}$ NaN3

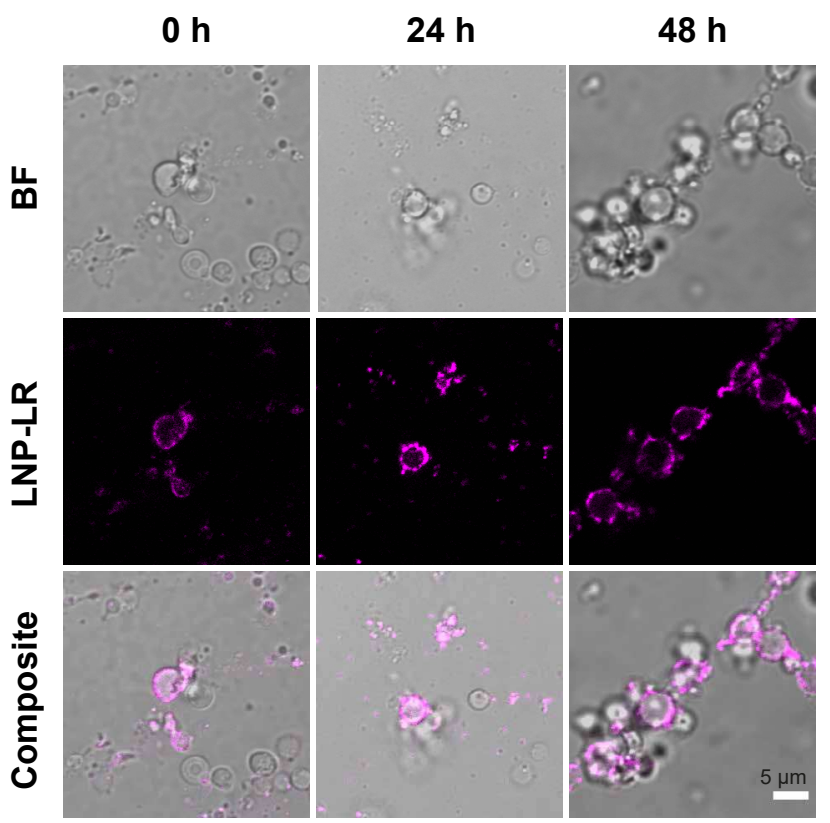

Figure 3. Localization of Lipid Nanoparticles in Internal L-form Vesicles

(A-B) Localization of LNP-LR (Lipid Nanoparticle containing 18:1 Liss Rhod PE; magenta) in internal vesicles of alpha (A) and alpha pIJ82-GFP (B) after overnight or 3-day incubation at $30^{\circ} \mathrm{C}$ respectively. Scale bar $=2 \mu \mathrm{m}$.

(C) Density profile plot and corresponding line selection of alpha pIJ82-GFP incubated with LNP-LR showing a decrease in cytoplasmic eGFP emission correlates with an increase in LNP-LR emission.

(D-E) Localization of LNP-LR during incubation with alpha at $4{ }^{\circ} \mathrm{C}(\mathrm{D})$ or in the presence of $2.5 \mathrm{mM}$ sodium azide at $30^{\circ} \mathrm{C}(\mathrm{E})$ after 0,24 and $48 \mathrm{~h}$ incubation. Similar results were obtained with 1 and $10 \mathrm{mM}$ sodium azide (data not shown). Scale bar $=5 \mu \mathrm{m}$. Note that incubation of L-forms with lipid nanoparticles (average size of $125 \mathrm{~nm}$ ) results in their localization inside internal vesicles, a process that can be inhibited by incubation at $4^{\circ} \mathrm{C}$ or sodium azide. 


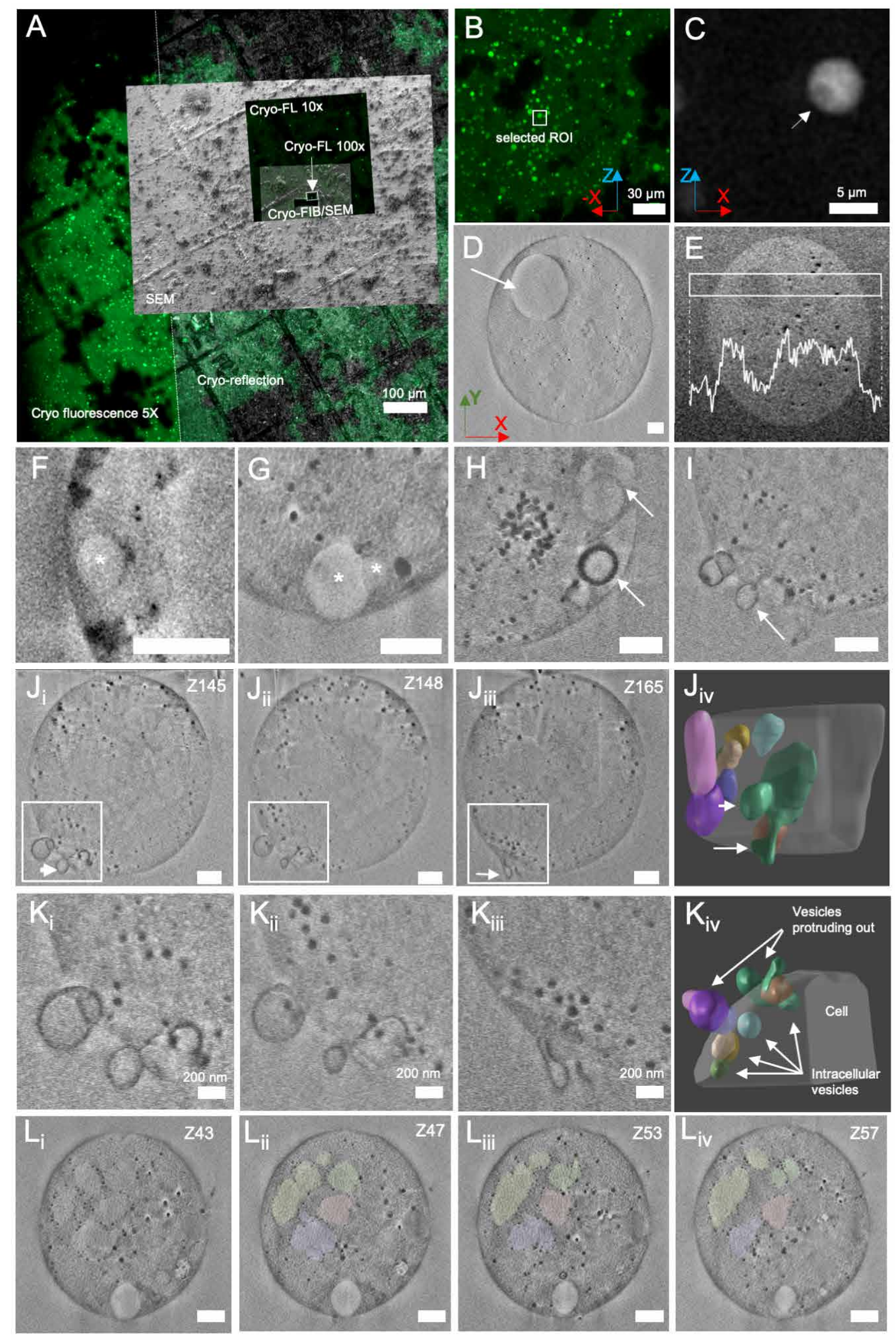


Figure 4. 3D Cryo-Fluorescence and Cryo-FIB-SEM of L-forms Reveals its Ultra-Structure in High Resolution

(A) Correlated fluorescence and electron micrographs of the frozen sample (Zen Connect image). The bright green dots indicate individual cells of alpha pIJ82-GFP. A finderTOP raster visible both in fluorescence and electron microscopy facilitates alignment between the two imaging modules. The small squares indicate different regions of interest, imaged at higher resolution. FL: Fluorescence light

(B) Higher resolution image of one region of interest, showing many fluorescent cells.

(C) L-form depicted by white box in B, showing intracellular dark sphere ( $\sim 1$ micrometer, white arrow).

(D) SEM image (SE, Inlens) of cell in C) with white arrow indicating the internal vesicle. The $\mathrm{X}, \mathrm{Y}$ and $\mathrm{Z}$ arrows in $\mathrm{B}, \mathrm{C}$ and $\mathrm{D}$ indicate the 3D orientation of the imaged cell as observed in 3D FIB-SEM.

(E) Superposition of five consecutive slices (backscattered images) of cell in D). Inset: Intensity plot profile (white) of the region in white box.

(F-I) FIB-SEM slices showing different types of internal vesicles. (F-G) Vesicles lining the cell membrane. Asterisks indicate vesicles. (H) Vesicle complex, note the different membrane thickness of vesicles indicated with white arrows. See also Figure S6D and Video S3. (I) Membrane protrusions as indicated with white arrow.

(J-K) Analysis of the interconnected vesicles of the cell in I). (Ji-iii) Three consecutive slices showing the interaction of different vesicles. Ki-iii show higher magnification of the regions in white boxes in Ji-iii, respectively). (Jiv, Kiv) 3D segmentation of Ki-iii. While some of the vesicles are intracellular, others protrude out of the cell. A complete connected vesicle structure is shown in green and is indicated by white arrows in I, Jiii and Jiv. See also Figure S6A-C and Video S2.

(L) Regions with different contrast are lined with black particles representing putative lipid bodies. The size distribution of the black particles is between 25 to $60 \mathrm{~nm}$. Scale bars represent $500 \mathrm{~nm}$ unless otherwise specified. 


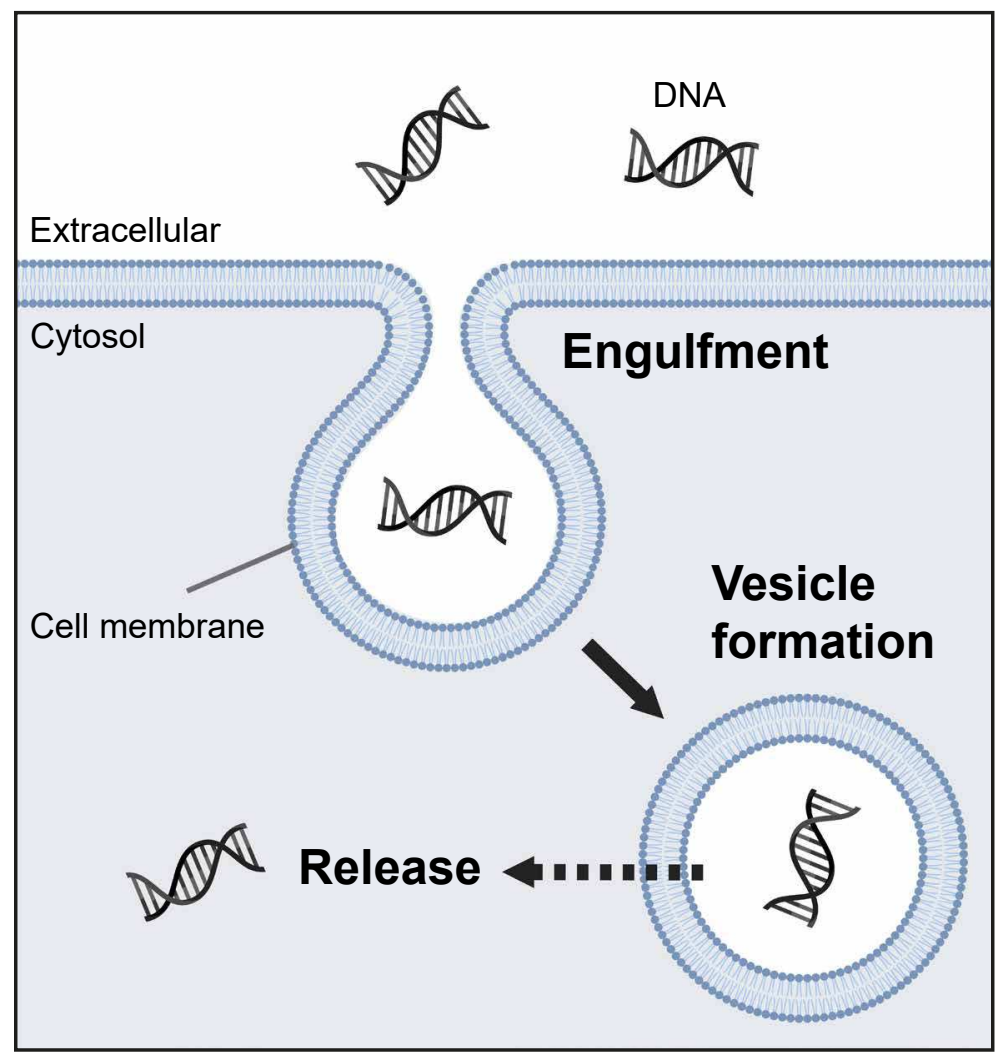

Figure 5. Proposed Model for DNA Uptake by Internal Vesicle Formation in L-forms

Excess membrane synthesis results in invagination of the cell membrane, leading to the formation of internal vesicles in L-forms. In this process, extracellular liquid containing DNA or other macromolecules is engulfed.

Finally, DNA is released from internal vesicles by an unknown process (indicated by dashed arrow), which may involve vesicle disruption. Image created with BioRender.com. 


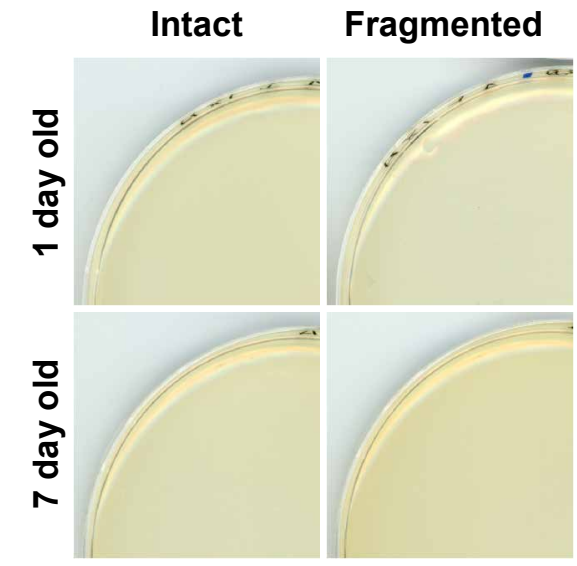

\section{S1C}

Unmethylated Methylated

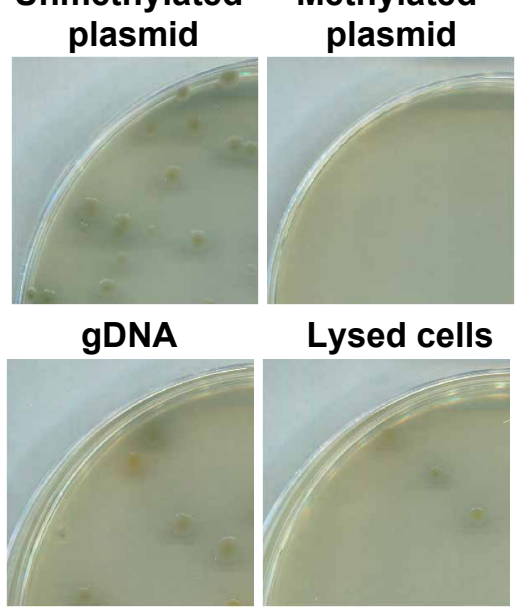

\section{S1E}

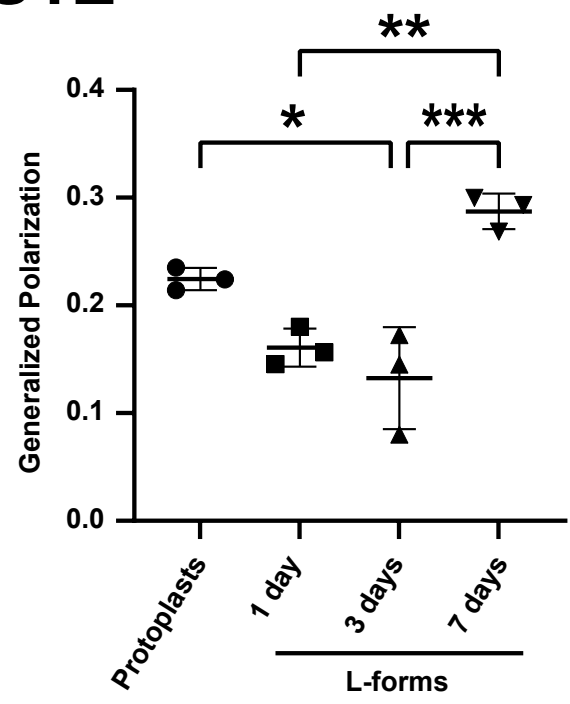

\section{S1B}

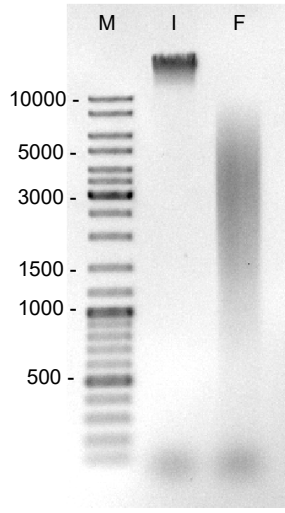

S1D
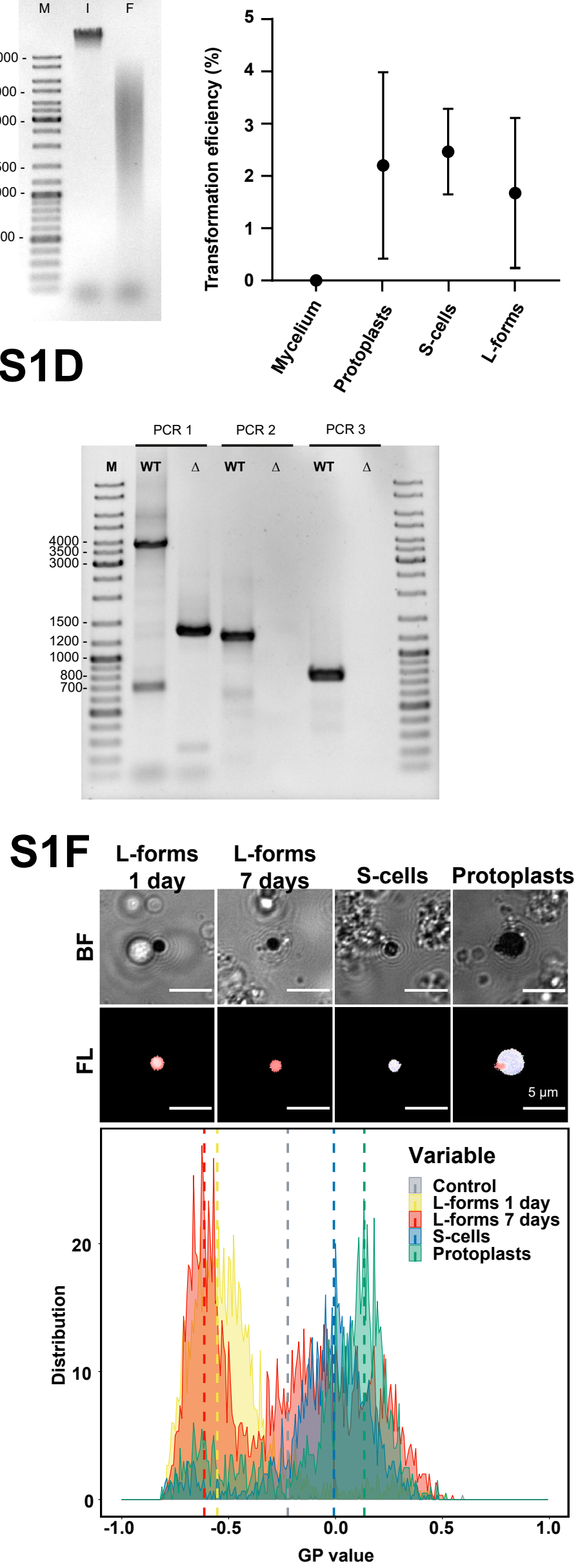
Figure S1. Analysis of Natural and Artificial DNA Uptake and Membrane Fluidity of Cell-Wall Deficient Cells and Confirmation of alpha $\Delta$ comEA/EC Mutant, Related to Figure 1

(A) (Left) Transformation plates showing absence of natural transformation upon incubation of 1-and 7-day old L-form alpha with intact or fragmented gDNA of alpha $\triangle \operatorname{ssg} B$ containing an apramycin resistance cassette. (Right) Gel electrograph of $100 \mathrm{ng}$ intact (I) or fragmented (F) gDNA of alpha $\Delta s g B$ as used in the natural transformation assay.

(B) Polyethylene glycol (PEG)-based transformation efficiency of $K$. viridifaciens mycelium, protoplasts, S-cells and L-forms using plasmid DNA (pRed*) containing an apramycin resistance gene, shown as the percentage of transformed colonies per total colony forming units. Data are represented as mean $\pm \mathrm{SD}, \mathrm{n}=3$.

(C) PEG-based transformation of alpha using unmethylated or methylated plasmid DNA (pRed*), gDNA or filter-sterilized salt-lysed cells from mutant line alphaAssgB.

(D) Gel electrograph of PCR products from three different PCR mixes to confirm the replacement of comEA and comEC by an apramycin resistance cassette. WT $=$ gDNA alpha; $\Delta=$ gDNA alpha $\triangle$ comEA/EC. Expected products: PCR $1 \mathrm{WT}=3676 \mathrm{bp}$, mutant $=1294 \mathrm{bp} ;$ PCR $2 \mathrm{WT}=1197 \mathrm{bp}$, mutant $=$ no amplification, $\mathrm{PCR} 3 \mathrm{WT}=745 \mathrm{bp}$, mutant $=$ no amplification.

(E) Generalized Polarization (GP) as measure of membrane fluidity of $K$. viridifaciens protoplasts, 1-, 3- and 7- day old L-form alpha. Lower GP indicates higher fluidity. *,** and *** indicate $\mathrm{P} \leq 0.05,0.01$ and 0.001 , respectively (one-way ANOVA, $\mathrm{F}(3,8)=19.49$, Tukey post-hoc test, $\mathrm{n}=3$ ). Data are represented as mean $\pm \mathrm{SD}$ with individual data points, $n=3$.

(F) Membrane fluidity of L-form alpha (1- and 7-day old), S-cells and protoplasts of $K$. viridifaciens. Top rows show brightfield images and heatmap of fluorescence emission (red to blue colour indicate GP values of -1.0 to 1.0 respectively) of representative cells stained with a Laurdan dye for quantifying the membrane fluidity $(\mathrm{BF}=$ brightfield, $\mathrm{FL}=$ fluorescence emission). Bottom panel shows frequency distributions of the Generalized Polarization (GP). Lower GP values correspond to higher membrane fluidity indicating that L-forms have more fluid membranes compared to S-cells and protoplasts. Control = cells imaged and analysed without Laurdan staining. 
S2A

BF

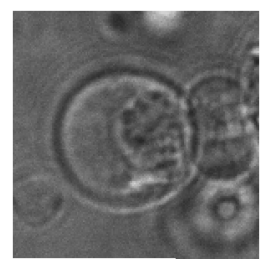

Cy5-DNA

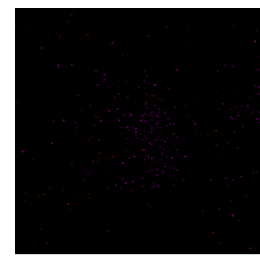

Composite

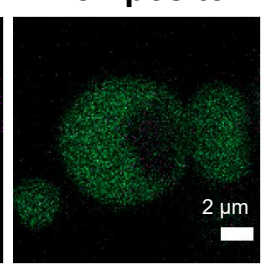

S2C

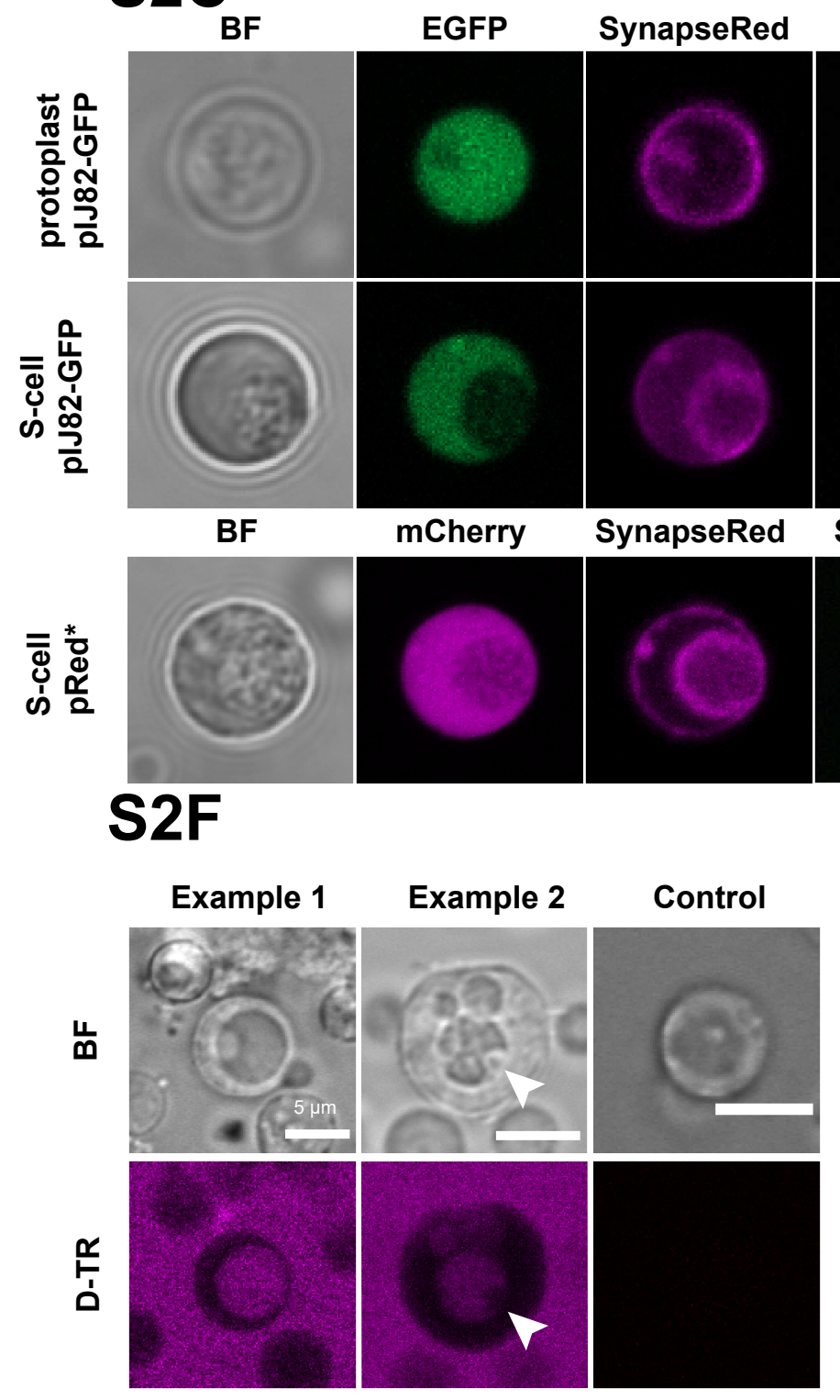

S2B alpha

BF
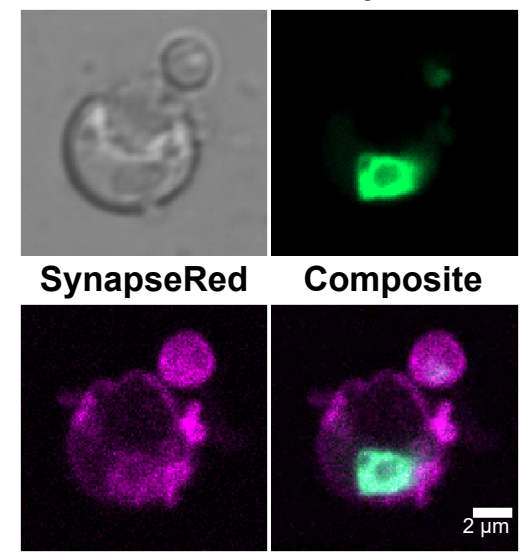

alpha pRed*

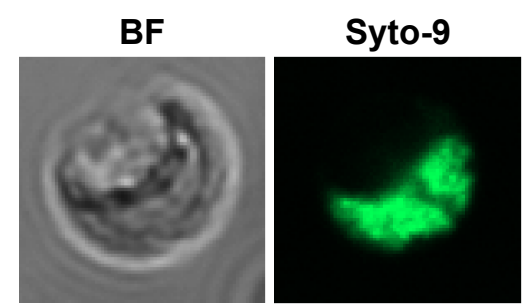

Composite
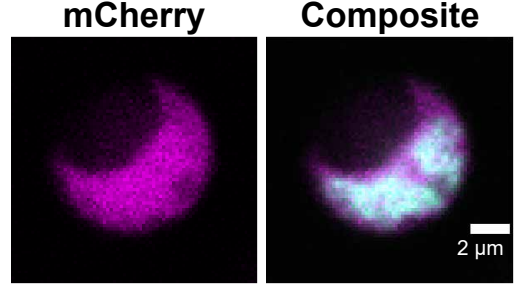

\section{S2D}

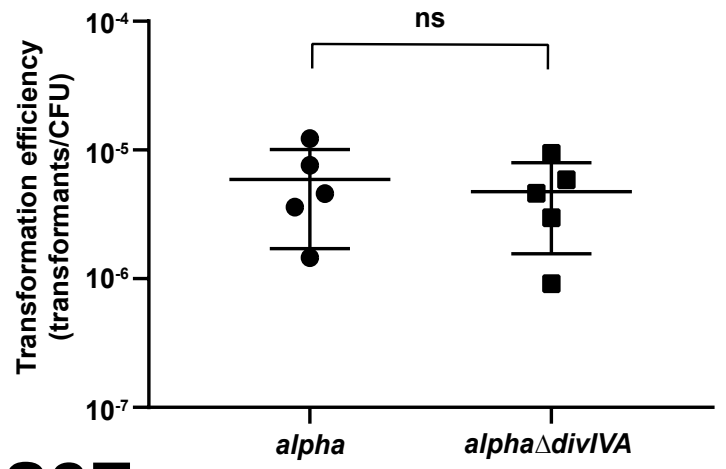

\section{S2E}

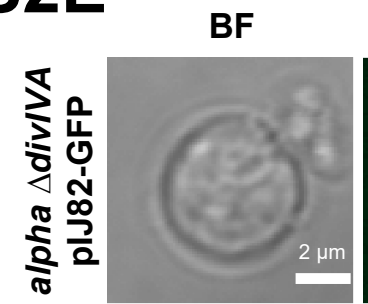

EGFP

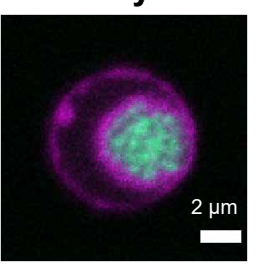

S2G

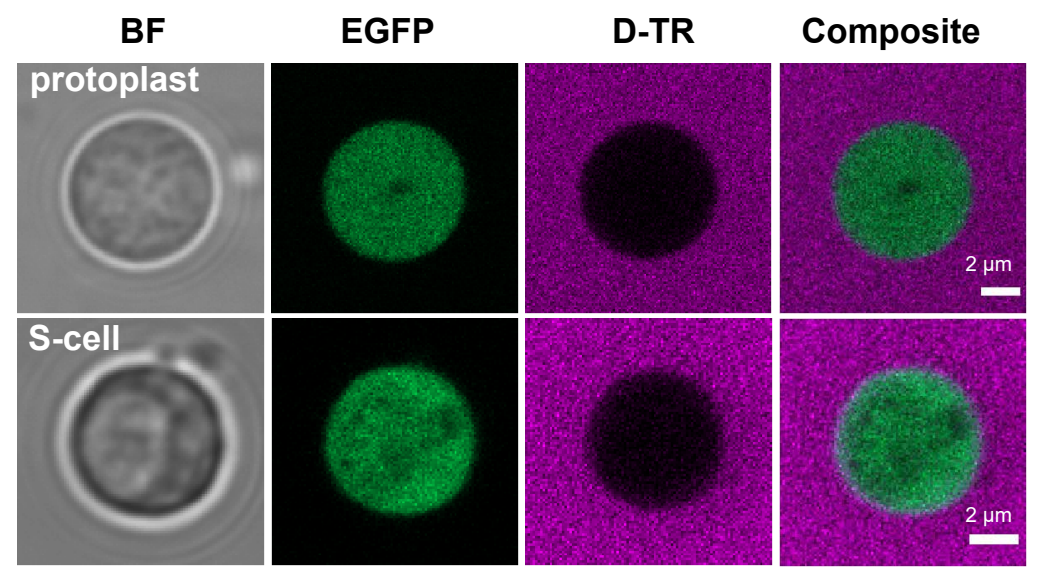


Figure S2. Analysis of DNA Content, Internal Vesicles and Uptake of D-TR of Cell-Wall Deficient Cells, and effect of divIVA deletion on DNA Uptake, Related to Figure 2

(A) alpha pIJ82-GFP incubated without Cy-5 DNA as fluorescence control.

(B) alpha and alpha pRed* stained with SYTO-9 (green) to indicate chromosomal DNA. alpha is stained with SynapseRed C2M (SynapseRed; magenta) to visualize cell membranes, whereas (absence of) cytosolic mCherry for alpha pRed* (magenta) indicates the presence of an internal vesicle.

(C) Protoplasts and S-cells of $K$. viridifaciens pIJ82-GFP producing cytosolic eGFP incubated with SynapseRed for $72 \mathrm{~h}$ (top rows), and S-cells of $K$. viridifaciens pRed* producing cytosolic mCherry incubated with SynapseRed (SR) and SYTO-9 for $72 \mathrm{~h}$ (bottom row). Chromosomal DNA is visualized using SYTO-9 staining. Note that presence of internal membrane structures causes a reduction in cytosolic fluorescence emission.

(D) Natural transformation assay of 7-day old alpha and alphaAdivIVA using pFL-ssgB. ns = not significant (two-tailed independent $\mathrm{t}$-test, $\mathrm{t}(8)=0.489, \mathrm{P}=0.638$ ). Data are represented as mean $\pm \mathrm{SD}$ with individual data points, $\mathrm{n}=5$.

(E) L-forms without DivIVA can produce internal vesicles as shown for 5-day old alphaAdivIVA pIJ82-GFP producing cytosolic eGFP. Scale bar $=2 \mu \mathrm{m}$.

(F) alpha incubated with (example 1 and 2) or without (control) Dextran Texas-Red (D-TR; magenta), showing the formation of internal vesicles filled with D-TR. The arrow indicates the presence of a non-fluorescent secondary internal vesicle inside an existing internal vesicle (example 2). Scale bar $=5 \mu \mathrm{m}$.

(G) Protoplasts and S-cells of $K$. viridifaciens pIJ82-GFP incubated with D-TR for $72 \mathrm{~h}$. Note that no internalization of D-TR was observed. 
S3A
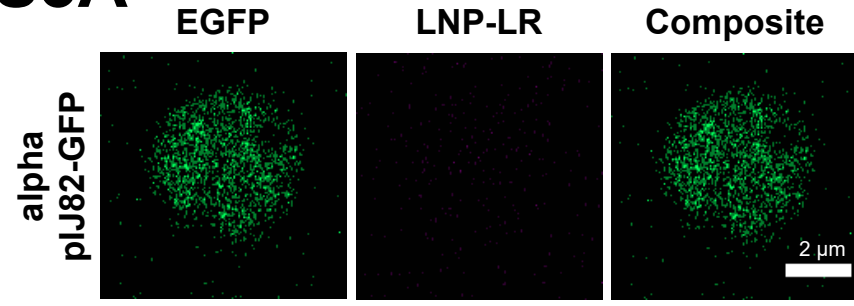

S3B

alpha with LNP-LR
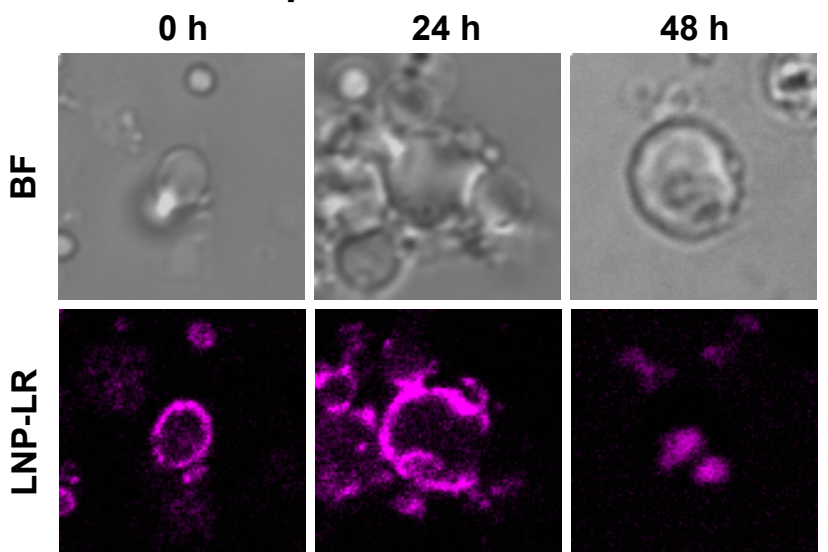

S3C

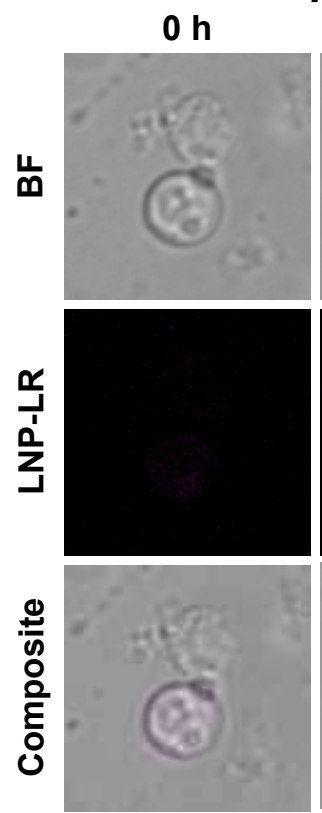

alpha with PBS

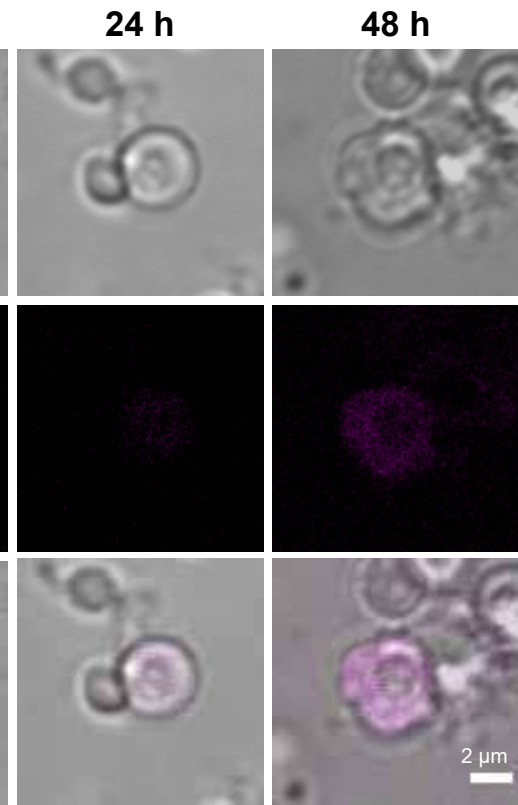

S3D

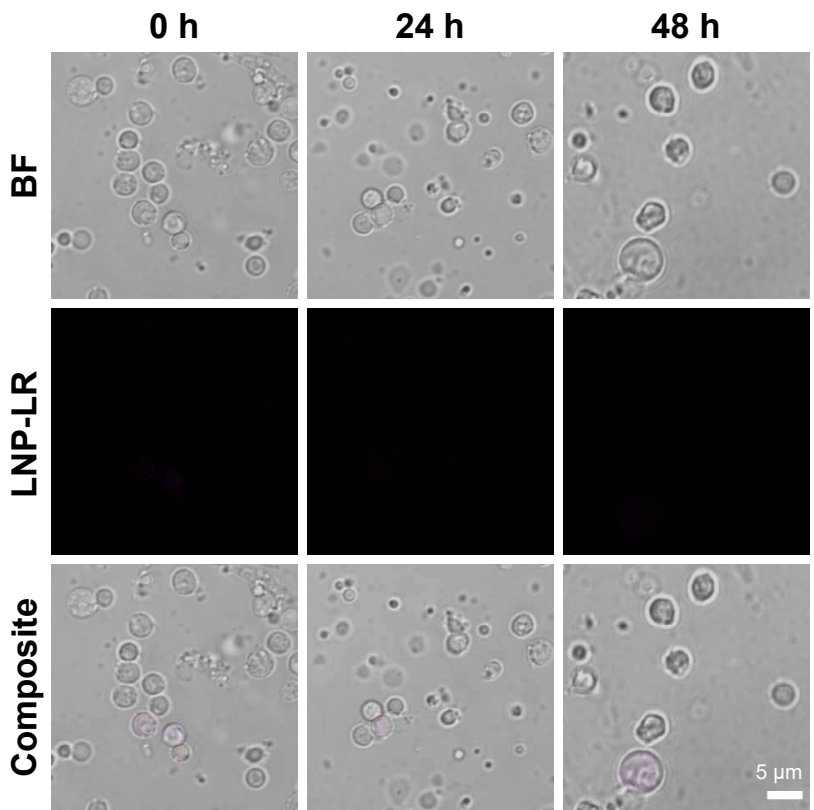

S3E alpha with PBS and $2.5 \mathrm{mM} \mathrm{NaN}_{3}$

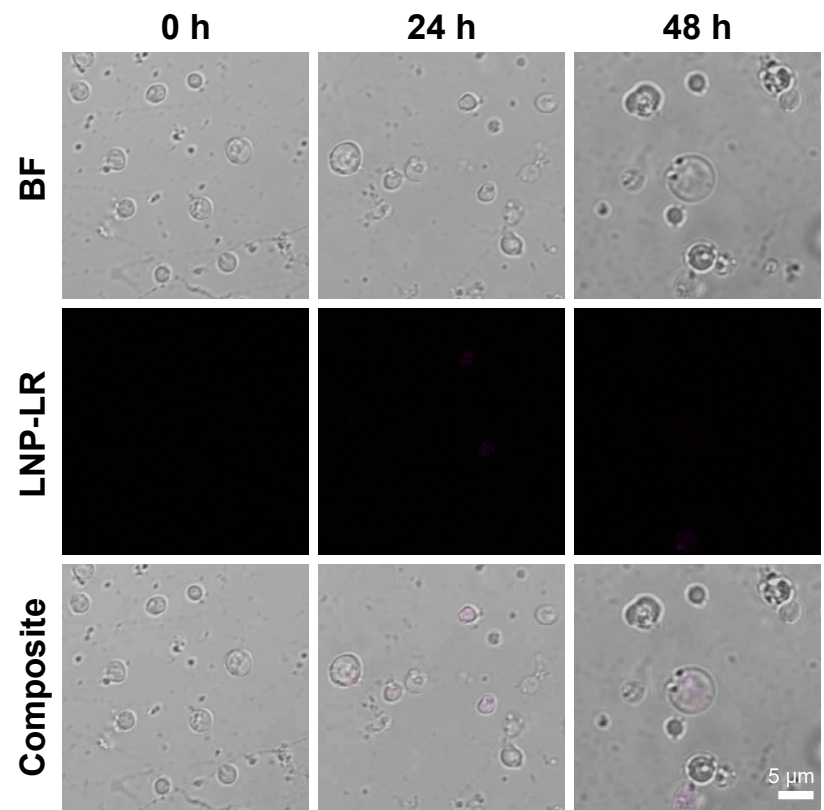

Figure S3. Uptake of LNP-LR by alpha, Related to Figure 3

(A) alpha pIJ82-GFP incubated without LNP-LR (LNP-Liss Rhod; magenta) as imaging control.

(B-C) alpha incubated with (B) or without (C) LNP-LR showing localization of LNP-LR after $0 \mathrm{~h}, 24 \mathrm{~h}$ and $48 \mathrm{~h}$ or examples of autofluorescence, respectively.

(D-E) alpha incubated with PBS at 4 degrees (D) or with PBS at $30^{\circ} \mathrm{C}$ in the presence of $2.5 \mathrm{mM}$ sodium azide (E) as control for fluorescence emission. Images were obtained after 0,24 and $48 \mathrm{~h}$ incubation. 

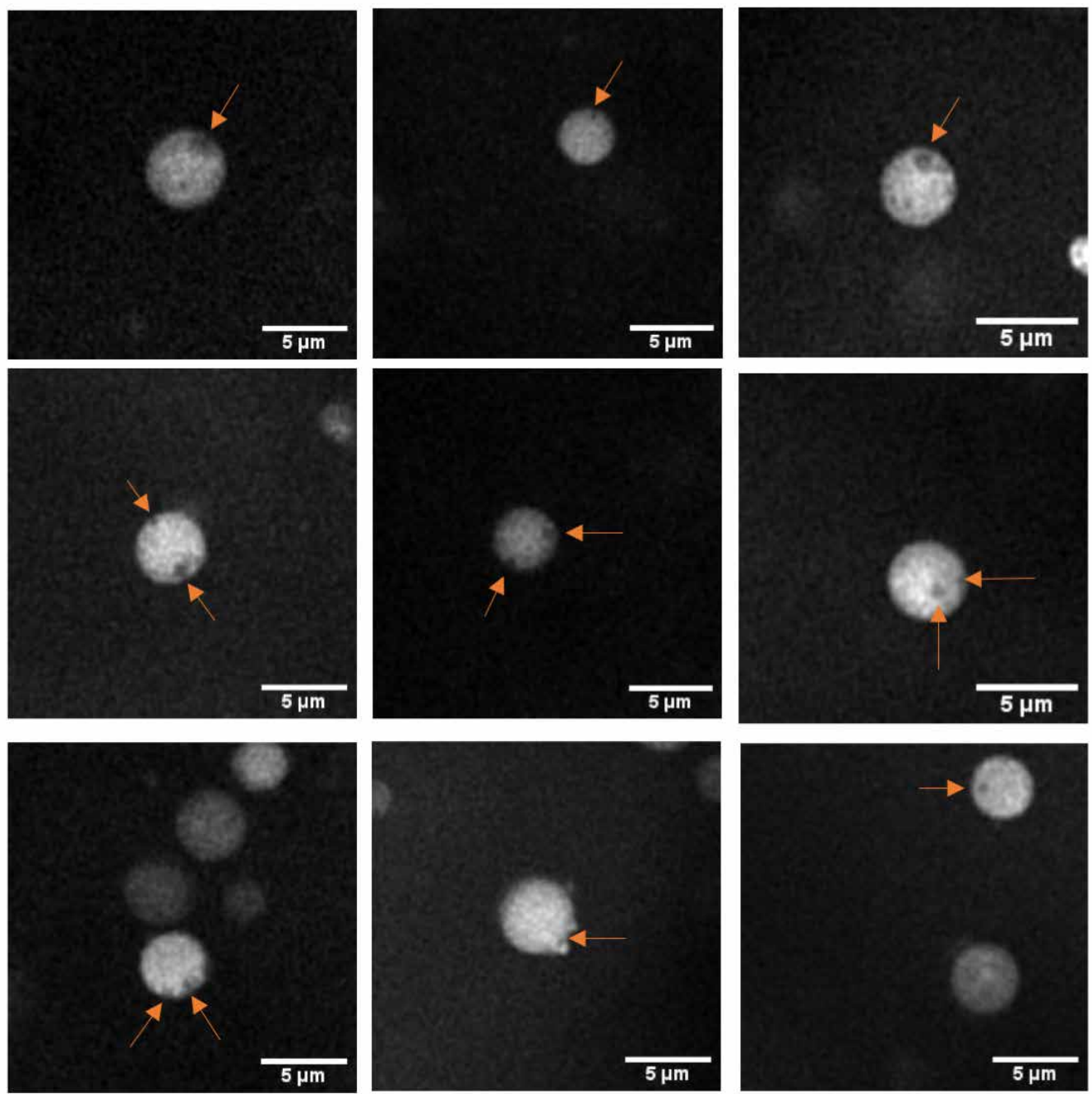

Figure S4. High Resolution Cryo-Fluorescence of L-forms, Related to Figure 4

alpha pIJ82-GFP imaged using cryo-fluorescence microscopy. Putative vesicles are indicated with arrows. Images were captured using the long distance 100x objective. 

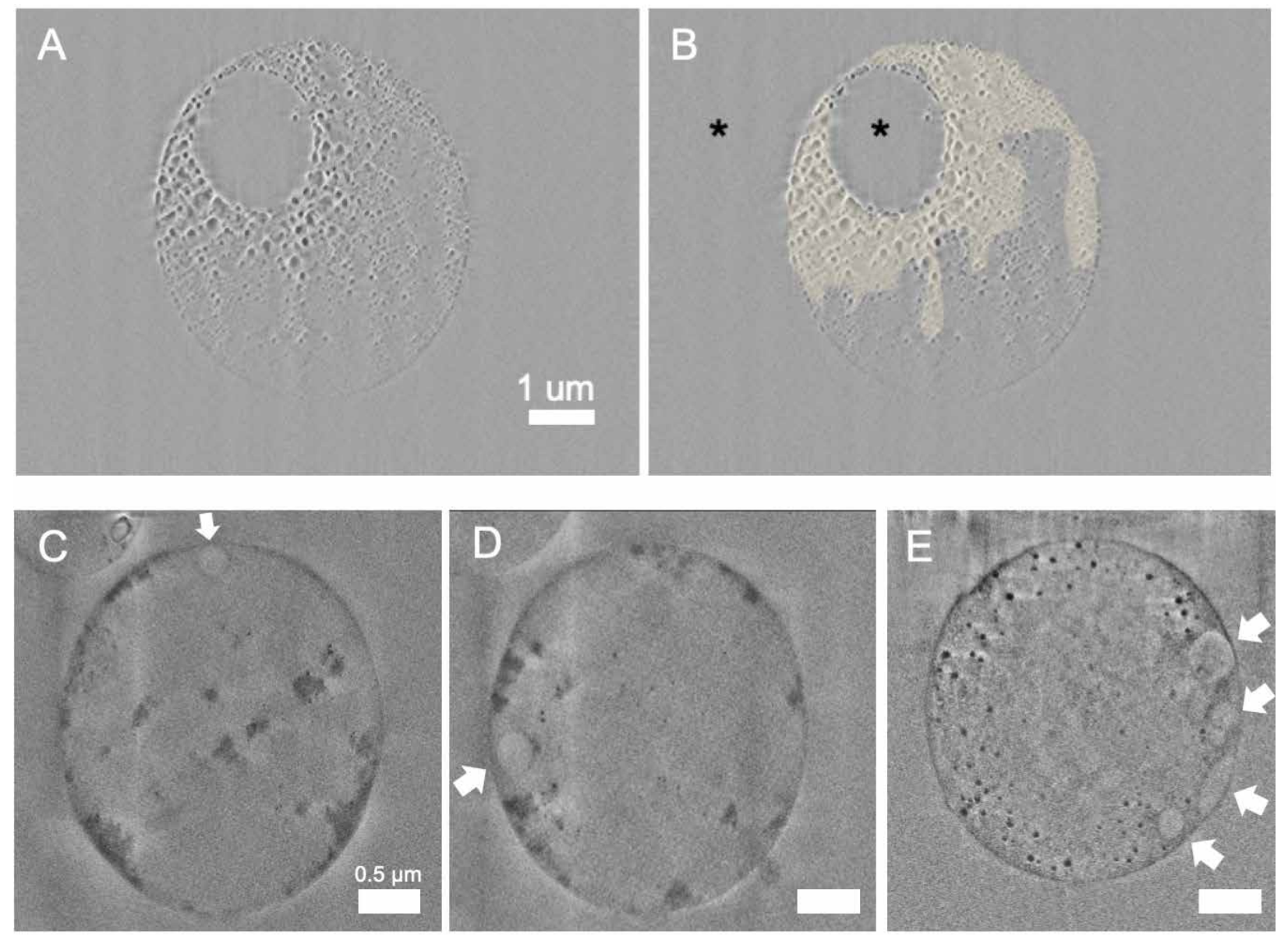

Figure S5. Over-dose experiment of L-form Cell using FIB-SEM, Related to Figure 4

(A-B) FIB-SEM slice of over-dose experiment using alpha pIJ82-GFP. The yellow colour in B) indicates areas with distinguished beam damage. The vesicle (black asterisk in the center of the cell) seems to be less to none affected by the dose, similar to the medium outside the cell (black asterisk outside of the cell). The image in Figure 4D is taken before this experiment, and Figure 4E is obtained by summing several slices deeper in the cell after acquiring this image.

(C-E) FIB-SEM slices of two cells (C-D correspond to the cell in Figure 4F and E corresponds to the cell in Figure 4 $\mathrm{H}-\mathrm{K})$, white arrows indicate vesicles that line the cell membrane. Scale bar in C-E is $0.5 \mu \mathrm{m}$. 

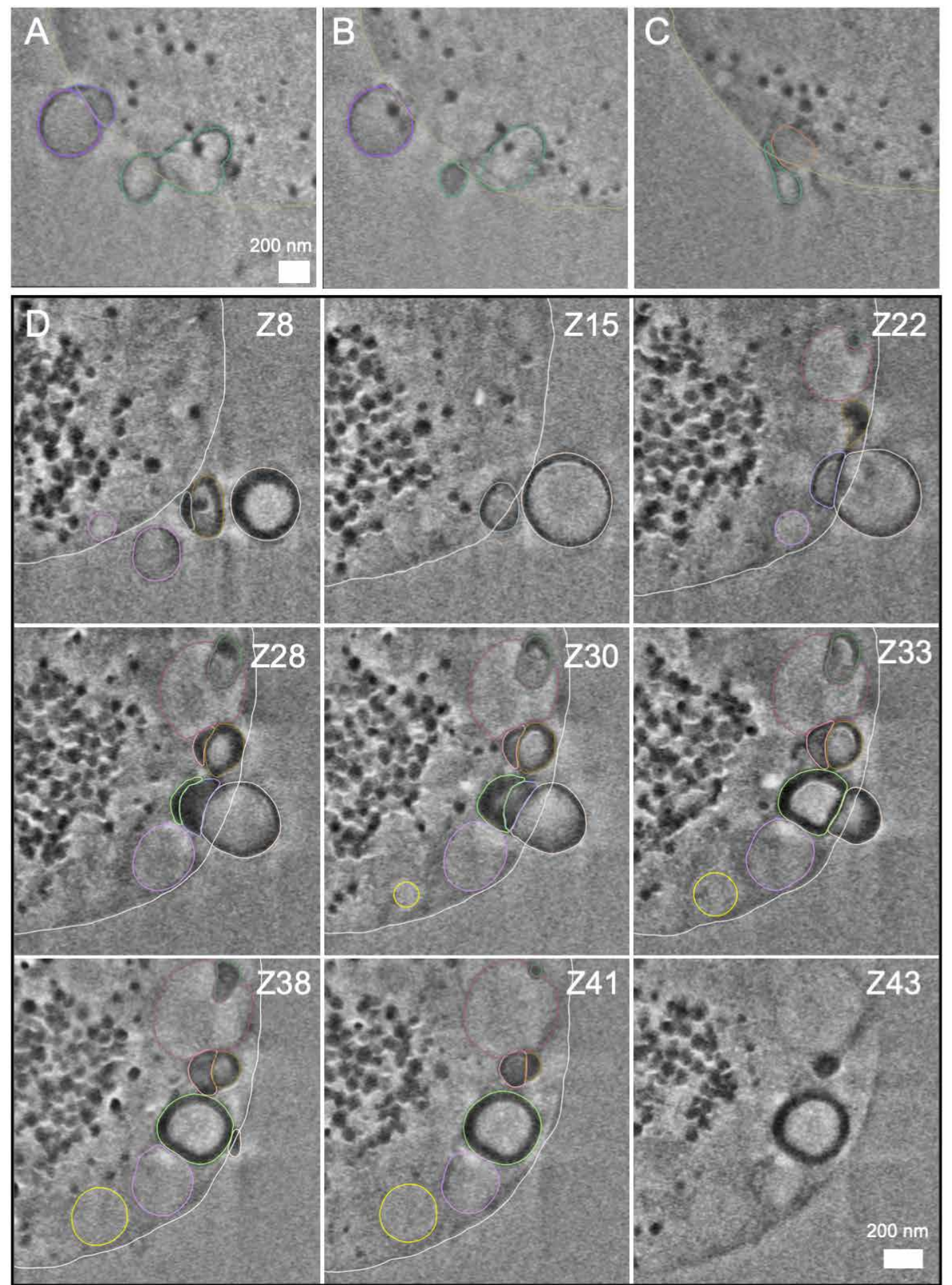

Figure S6. 3D Segmentation of L-form Vesicles, Related to Figure 4

(A-C) FIB-SEM slices corresponding to Figure 4I, Jiv and Ki-iii, respectively. Colours correspond to the segmented colours in Figure 4Kiv. Vesicles that are budding out the cells are connected to other vesicles or are elongated inside the cell. Scale bar $=200 \mathrm{~nm}$. See also Video S2.

(D) FIB-SEM slices corresponding to the cell in Figure 4H. Z-number indicates the slice. Colours indicate individual vesicles. See also Video S3. 


\section{Supplementary Files}

This is a list of supplementary files associated with this preprint. Click to download.

- MovieS1.avi

- Movies2.avi

- MovieS3.avi 